\title{
Large eddy simulation investigations of periodic cavitation shedding with special emphasis on three-dimensional asymmetry in a scaled-up nozzle orifice
}

Citation for published version (APA):

Bai, W., Tijsseling, A. S., Wang, J., Duan, Q., \& Zhang, Z. (2021). Large eddy simulation investigations of periodic cavitation shedding with special emphasis on three-dimensional asymmetry in a scaled-up nozzle orifice. Journal of Fluids Engineering, Transactions of the ASME, 143(7), [071401].

https://doi.org/10.1115/1.4050136

Document license:

TAVERNE

DOI:

$10.1115 / 1.4050136$

Document status and date:

Published: 01/07/2021

Document Version:

Publisher's PDF, also known as Version of Record (includes final page, issue and volume numbers)

Please check the document version of this publication:

- A submitted manuscript is the version of the article upon submission and before peer-review. There can be important differences between the submitted version and the official published version of record. People interested in the research are advised to contact the author for the final version of the publication, or visit the DOI to the publisher's website.

- The final author version and the galley proof are versions of the publication after peer review.

- The final published version features the final layout of the paper including the volume, issue and page numbers.

Link to publication

\footnotetext{
General rights

- You may freely distribute the URL identifying the publication in the public portal. follow below link for the End User Agreement:

www.tue.nl/taverne

Take down policy

If you believe that this document breaches copyright please contact us at:

openaccess@tue.nl

providing details and we will investigate your claim.
}

Copyright and moral rights for the publications made accessible in the public portal are retained by the authors and/or other copyright owners and it is a condition of accessing publications that users recognise and abide by the legal requirements associated with these rights.

- Users may download and print one copy of any publication from the public portal for the purpose of private study or research.

- You may not further distribute the material or use it for any profit-making activity or commercial gain

If the publication is distributed under the terms of Article $25 \mathrm{fa}$ of the Dutch Copyright Act, indicated by the "Taverne" license above, please 


\author{
Wenjie Bai \\ School of Chemical Engineering \\ and Technology, \\ Xi'an Jiaotong University, \\ Xi'an 710049, China \\ e-mail: bwj0319@gmail.com \\ Arris S. Tijsseling \\ Department of Mathematics and \\ Computer Science, \\ Eindhoven University of Technology, \\ P.0. Box 513 \\ Eindhoven, 5600 MB, The Netherlands \\ e-mail: a.s.tijsseling@tue.n \\ Jun Wang \\ Department of Engineering Physics, \\ University of Wisconsin, \\ Madison, WI 53706 \\ e-mail: jwang564@wisc.edu \\ Quan Duan ${ }^{1}$ \\ School of Chemical Engineering \\ and Technology, \\ X'an Jiaotong University, \\ X'an 710049, China \\ e-mail: quanduan@mail.xjtu.edu.cn \\ Zaoxiao Zhang ${ }^{1}$ \\ School of Chemical Engineering \\ and Technology, \\ Xi'an Jiaotong University, \\ Xi'an 710049, China \\ e-mail: zhangzx@mail.xjtu.edu.cn
}

Large Eddy Simulation Investigations of Periodic Cavitation Shedding With Special Emphasis on ThreeDimensional Asymmetry in a Scaled-Up Nozzle Orifice

The periodic shedding of cloud cavitation in a nozzle orifice has a significant influence on the flow field and may have destructive effects. Most of the existing research on the shedding of cloud cavitation in an orifice is based on experimental visualization with a focus on the two-dimensional (2D) motion of the re-entrant jet and the shedding mechanism. However, the actual cloud cavitation shedding in an orifice is a complex threedimensional $(3 D)$ process. Some limited signs of three-dimensionality and asymmetry in cylindrical orifices have been detected recently, but the $3 D$ shedding characteristics remain unclear. In this paper, the cavitation regimes and periodic shedding process in the scaled-up nozzle orifice used by the Stanley experiment were simulated with large eddy simulation (LES). The re-entrant jet and periodic shedding mechanism, as well as, the shedding frequency, were analyzed from $2 D$ and $3 D$ perspectives. The main results show that the simulated cavitation regimes and the $2 D$ periodic shedding mechanism agree fairly well with the experimental observations, but more $3 D$ features are revealed. By analyzing the $3 D$ shedding process and the three-dimensionality caused by the inclination of the closure line, the three-dimensional asymmetric shedding mode with phase difference $\pi$ is revealed. Based upon this finding, the shedding frequency, and Strouhal number are calculated. The corresponding relationships between shedding frequencies and the frequency peaks of the power spectrum density (PSD) for pressure fluctuations are also confirmed. These results extend the understanding of the unsteady cavitating flow within nozzle orifices from 2D to 3D patterns. [DOI: 10.1115/1.4050136]

\section{Introduction}

The occurrence of cavitation within nozzles has a crucial impact on the flow field for various hydraulic systems such as dump throttles of liquid propellant rocket engines, orifices of hydraulic jacks, and injector nozzles of diesel engines [1-3]. Especially for the latter, many researchers have shown that cavitation within the nozzles significantly enhances the atomization of high-speed liquid jets [4], reduces jet breakup length [5,6], and increases jet spray angle [7,8]. Meanwhile, the damage risks of cavitation such as erosion and vibration will always be there during bubble collapse. These destructive effects affect nozzle performance and reduce the equipment lifespan [9-12]. Therefore, for nozzle orifice design, it is essential to understand the cavitating flow characteristics for utilizing cavitating flow and minimizing its negative effects.

Due to the low diameter which is about $200 \mu \mathrm{m}$ and the high operation pressure which can reach $220 \mathrm{MPa}$, experiments with small-scale nozzles often use plane orifices with two-dimensional (2D) flow [13-15]. However, the 2D flow in a plane orifice is different from that in a cylindrical orifice used as an injector nozzle. In order to more accurately observe the cavitating flow in cylindrical orifices used in practice, most experiments are conducted with scaled-up long orifices [16-21]. Although it is impossible to

\footnotetext{
${ }^{1}$ Corresponding authors.

Contributed by the Fluids Engineering Division of ASME for publication in the Journal OF Fluids EngineERING. Manuscript received March 26, 2020; final manuscript received February 6, 2021; published online April 9, 2021. Assoc. Editor: Wayne Strasser.
}

achieve true similarity to the small-scale nozzles, these scaled-up experiments are very useful for exploring the macroscopic cavitation structures and transitions [16].

In cylindrical orifice flow, cavitation initiates at the high shear layer and recirculation near the entrance where the local static pressure is below the vapor pressure. Cavitation bubbles begin to grow at the nucleation sites which may be the microscopic surface roughness of the wall or the impurities and free gases in the liquid. These bubbles coalesce to form large cavitation structures and collapse in the high-pressure region downstream. The extent of cavitation can be described by the cavitation number $\sigma$ which has many different forms in the literature. In this work, we use the form presented by Nurick [22], which was used by Stanley $[16,17]$. It is defined as

$$
\sigma=\frac{P_{1}-P_{v}}{P_{1}-P_{2}}
$$

where $P_{1}$ is the inlet pressure (injection pressure), $P_{2}$ is the outlet pressure (ambient pressure), and $P_{v}$ is the vapor pressure of the liquid.

According to the previous visualization observations $[16,17$, $20,23]$, the transition of cavitation regime in long cylindrical orifices can be roughly summarized as follows: with the decrease of cavitation number $\sigma$, the cavitation regime starts from incipient cavitation, then goes through partial cavitation, developed cavitation, supercavitation, and finally develops into hydraulic flip for nonsubmerged jet or jet cavitation for submerged jet. For supercavitation and hydraulic flip, the cavitation length $L_{\text {cav }}$, which was 
clearly defined by Stanley as the distance from the orifice entrance to the last point where cavitation bubbles can be identified [17], is equal to or greater than the orifice length $L$. For incipient cavitation, the cavitation length $L_{\text {cav }}$ is close to zero. In the case of partial cavitation and developed cavitation, $L_{\mathrm{cav}}$ is in the range of 0 to $L$. Some studies $[16,17,19,21]$ have revealed that for orifices with various length-to-diameter ratios, the cavitation length follows the cavitation regime transition with a similar pattern.

Under the condition of partial cavitation, periodic shedding of cavitation structures has been observed for cavitating flow in large-scale long orifices $[16,17,19,24]$. The attached cavity initiated at the entrance, which is known as sheet cavity, grows to a certain size and then being severed to form cloud cavitation which moves downstream and eventually collapses periodically. This periodic shedding phenomenon, which is often referred to as the transition from sheet to cloud cavitation, is well-reported for hydrofoils and convergent-divergent channels. Numerous studies have shown that the two main mechanisms including re-entrant jet [25-27], which is a liquid jet beneath the attached cavity in the direction opposite to the bulk flow, and pressure waves generated by the collapse of cloud cavitation [28-30], are central to the periodic shedding process. However, only a few investigations have studied the periodic shedding process in long cylindrical orifices. Based on high-speed visualization, Sato and Saito [19] concluded that in a shedding period, the ratio of growing time of the attached cavity to the traveling time of the re-entrant jet is two, which is similar to the result of Le et al. [25]. Using high-speed visualizations in a long cylindrical orifice, Stanley [17] revealed a complex mechanism of periodic shedding caused by a combination of a traveling wave style deformation of the cavity interface and the translational motion of the re-entrant jet, each with distinctly different velocities.

During partial cavitation, the cavitating flows have a complex behavior where the cavity is characterized by a strong unsteadiness, transient cavities shedding downstream, and a completely three-dimensional (3D) flow even in a 2D configuration [31]. For hydrofoils, the three-dimensionality caused by the inclined cavity closure line has been well reported and discussed [32-34]. Although there is almost no relevant research on the threedimensionality of the shedding process in cylindrical orifices due to the difficulties of experimental observation, a few experimental and numerical results have shown some signs. Stanley [17] observed asymmetrical cloud shedding in a cylindrical orifice caused by the diagonal motion of the re-entrant jet. He thought that this is similar to the three-dimensionality of the re-entrant jet on a swept hydrofoil caused by the inclination of the closure line, as discussed by De-Lange and De-Bruin [33] and Duttweiler and Brennen [34]. Ahuja et al. [35] simulated the asymmetry of cloud cavitation and speculated that this asymmetry may be responsible for flapping modes or azimuthal modes. But the exact pattern and details of the shedding with three-dimensional asymmetry are not clear and further investigations are needed.

Another important issue accompanying the shedding process is the determination of the shedding frequency. The most common and essential method is to calculate the time period and frequency of the shedding process by frame-frame variation based on highspeed visualization. Le et al. [25] and Sato and Satio [19] used this method to determine the time period and shedding frequency as well as Strouhal number $S_{t}$ for hydrofoil and cylindrical orifice, respectively. The other common approach is to monitor the grayscale variation of the selected regions and determine the frequency by fast Fourier transform or power spectral density (PSD). Charrière et al. [31] and Willian [36] selected an appropriate location in the collapse region of a venturi in simulation and visualization results, respectively. Other auxiliary methods include monitoring the cavitation length variation [2] and fluctuation pressure during the shedding process $[2,37]$. It is worth noting that these works pertain to static feed conditions, and the cavitating flow exhibit a steady shedding frequency. For unsteady atomization, it would require a different type of analysis for differentiating between the system harmonics and that of the cavitation [38-40].

As we know, by using either a backlit or front-lit high-speed camera, it is much more difficult to visualize the completely 3D cavitating flow with strong unsteadiness in a cylindrical orifice than that of the swept hydrofoil. Thus, numerical simulation is a better way to understand the shedding process with 3D asymmetry in a cylindrical orifice. The Reynolds-averaged Navier-Stokes (RANS) approach, like $\kappa-\varepsilon$ models, does not address the influence of turbulent fluctuations on the onset and development of cavitation, which leads to a steady-state solution. It seems that the shedding of cloud cavitation and re-entrant jet cannot be predicted well, and the large eddy simulation (LES) method was recommended [2]. By using the LES method, Gnanaskandan et al. [41] and Bhatt et al. [42] obtained a good agreement with the experimental results of Ganesh et al. [28,29] for the transition from sheet to cloud cavitation within a convergent-divergent channel. Compared with the experiment, Ji [43] and Long [44] used LES to reproduce the cavitation shedding process on hydrofoil very well. There have been some comparative studies of the various cavitation models [45-48]. Frikha et al. [46] presented a study of several void- fraction transport-equation-based cavitation models on twodimensional foils. Their results demonstrated a large resemblance between the models, and they clarified that modifying the model parameters changes the cavity shape and structure. The parameter bubble-number-density $n_{b}$ in Schnerr and Sauer's model can be tuned to some reference measurements and then be used for the simulation of cavitating liquids in arbitrary flow configurations $[49,50]$.

In this work, we investigate by LES the periodic shedding process in a long cylindrical orifice with special emphasis on the $3 \mathrm{D}$ asymmetry. In addition, the determination of shedding frequency based on the transient characteristics of the shedding process and the PSD of pressure fluctuations were examined. The paper is organized as follows. Section 2.1 explains the cavitation model. Section 2.2 describes the governing equations of LES. Section 2.3 presents the simulation settings and mesh studies. Section 3.1 validates the effectiveness of the present numerical method by comparing the simulation and experimental results with respect to the cavitation regimes in the cylindrical orifice. Section 3.2 analyzes the re-entrant jet motion and periodic shedding process. Section 3.3 discusses the three-dimensionality caused by the inclined cavitation closure line and the 3D asymmetric shedding mode. The shedding frequency of cloud cavitation is also estimated and discussed in Sec. 3.4. Section 4 provides a brief conclusion.

\section{Numerical Modeling}

In this work, LES simulations are performed with the computational fluid dynamics (CFD) code ANSYS FLUENT 17.0. The working fluid (distilled water, $18^{\circ} \mathrm{C}$ ) is considered to be isothermal. According to the previous research [1,2,51], a homogeneous multiphase mixture flow model is considered to be appropriate for the significant variation of densities in the process of phase transition. In the present nozzle flow, the high level of turbulence does not allow large bubble growth. It is therefore assumed that the bubbles have the same velocity as the liquid. Consequently, there is no need to solve for the slip velocity and the independent momentum of both phases [52]. The Schnerr-Sauer cavitation model, which has been validated in similar research $[2,51,53,54]$, has been adopted to capture cavitation formation.

2.1 Cavitation Model. According to Schnerr and Sauer [55-57], the equation for the vapor volume fraction has the general form

$$
\frac{\partial}{\partial t}\left(\alpha \rho_{v}\right)+\nabla \cdot\left(\alpha \rho_{v} \mathbf{V}_{v}\right)=\frac{\rho_{v} \rho_{l}}{\rho} \frac{\mathrm{d} \alpha}{\mathrm{d} t}
$$

where $\alpha$ is the vapor volume fraction, $\rho_{v}$ is the vapor density, $\rho_{l}$ is the liquid density and $\rho$ is the mixture density, and $\mathbf{V}_{v}$ is the velocity of the gaseous phase. The net mass source term $S$ is: 


$$
S=\frac{\rho_{v} \rho_{l}}{\rho} \frac{\mathrm{d} \alpha}{\mathrm{d} t}
$$

By assuming that the bubble is spherical, Schnerr and Sauer use the following expression to connect the vapor volume fraction to the number of bubbles per volume of liquid:

$$
\alpha=\frac{n_{b}(4 / 3) \pi R_{B}^{3}}{1+n_{b}(4 / 3) \pi R_{B}^{3}}
$$

where $n_{b}$ is the number of bubbles per unit volume of liquid (the bubble number density) and $R_{B}$ is the bubble radius. Based on the generalized Rayleigh-Plesset equation [58], neglecting secondorder terms and surface tension, the bubble dynamics equation is simplified to

$$
\frac{\mathrm{d} R_{B}}{\mathrm{~d} t}=\sqrt{\frac{2\left(p_{v}-p\right)}{3}}
$$

where $p_{v}$ is the vapor pressure and $p$ is pressure. By combining Eqs. (3)-(5), the expression for net mass transfer is derived

$$
S=\frac{\rho_{v} \rho_{l}}{\rho} \alpha(1-\alpha) \frac{3}{R_{B}} \sqrt{\frac{2}{3} \frac{\left(p_{v}-p\right)}{\rho_{l}}}
$$

The bubble radius $R_{B}$ is given by rewriting Eq. (4)

$$
R_{B}=\left(\frac{\alpha}{1-\alpha} \frac{3}{4 \pi} \frac{1}{n_{b}}\right)^{\frac{1}{3}}
$$

As shown in Eq. (6), the mass transfer rate in the Schnerr and Sauer model is proportional to $\alpha(1-\alpha)$. The function $f\left(\alpha, \rho_{v}, \rho_{l}\right)=\frac{\rho_{v} \rho_{l}}{\rho} \alpha(1-\alpha)$ approaches zero when $\alpha=0$ and $\alpha=1$, and reaches the maximum when $\alpha=\frac{1}{2}$.

Equation (6) is for the evaporation process, involving vapor formation. It is also used to model condensation the process, involving vapor collapse. The final form of the model is as follows:when $p_{v} \geq p$

$$
S_{e}=\frac{\rho_{v} \rho_{l}}{\rho} \alpha(1-\alpha) \frac{3}{R_{B}} \sqrt{\frac{2}{3} \frac{\left(p_{v}-p\right)}{\rho_{l}}}
$$

when $p_{v} \leq p$

$$
S_{c}=\frac{\rho_{v} \rho_{l}}{\rho} \alpha(1-\alpha) \frac{3}{R_{B}} \sqrt{\frac{2}{3} \frac{\left(p-p_{v}\right)}{\rho_{l}}}
$$

where $S_{e}$ is the evaporation source term and $S_{c}$ is the condensation source term.

In this model, the only parameter which must be determined is the bubble number density $n_{b}$. If no bubbles are created or destroyed, the bubble number density would be constant. In the simulation of distilled water, the default value of $n_{b}=1 \times 10^{13}$ was used based on the recommendation in similar studies $[49,50]$.

2.2 Governing Equations and Large Eddy Simulation. The basic governing equations including the mass and momentum conservation equations are as follows:

$$
\begin{gathered}
\frac{\partial \rho}{\partial t}+\frac{\partial\left(\rho u_{j}\right)}{\partial x_{j}}=0 \\
\frac{\partial\left(\rho u_{i}\right)}{\partial t}+\frac{\partial\left(\rho u_{i} u_{j}\right)}{\partial x_{j}}=-\frac{\partial p}{\partial x_{i}}+\frac{\partial}{\partial x_{j}}\left(\mu \frac{\partial u_{i}}{\partial x_{j}}\right)
\end{gathered}
$$

The dynamic viscosity $\mu$ and mixture density $\rho$ are defined as

$$
\begin{aligned}
& \mu=\alpha \mu_{v}+(1-\alpha) \mu_{l} \\
& \rho=\alpha \rho_{v}+(1-\alpha) \rho_{l}
\end{aligned}
$$

By applying a Favre-filtering operation to Eqs. (10) and (11), the Favre Filtered governing equations are obtained

$$
\begin{gathered}
\frac{\partial \rho}{\partial t}+\frac{\partial\left(\rho \bar{u}_{j}\right)}{\partial x_{j}}=0 \\
\frac{\partial\left(\rho \bar{u}_{i}\right)}{\partial t}+\frac{\partial\left(\rho \bar{u}_{i} \bar{u}_{j}\right)}{\partial x_{j}}=-\frac{\partial \bar{p}}{\partial x_{i}}+\frac{\partial}{\partial x_{j}}\left(\mu \frac{\partial \bar{u}_{i}}{\partial x_{j}}\right)-\frac{\partial \tau_{i j}}{\partial x_{j}}
\end{gathered}
$$

where the over-bars denote filtered quantities. The extra nonlinear term, $\tau_{i j}$, is expressed as

$$
\tau_{i j}=\rho\left(\overline{u_{i} u_{j}}-\bar{u}_{i} \bar{u}_{j}\right)
$$

which are called the subgrid-scale (SGS) stresses and need to be modeled. A common SGS model is the eddy-viscosity model, which assumes that the SGS stresses are proportional to the modulus of the strain rate tensor $S_{i j}$ of the filtered large-scale flow

$$
\tau_{i j}-\frac{1}{3} \tau_{k k} \delta_{i j}=-2 \mu_{t} \bar{S}_{i j}
$$

where $\bar{S}_{i j}$ is the rate-of-strain tensor for the resolved scale and the subgrid-scale turbulent viscosity $\mu_{t}$ is closed by LES wall-adapting local eddy-viscosity (WALE) model [59]. The main advantage of the WALE model is its capability to reproduce the laminar to turbulent transition and the design of the model to return the correct wall-asymptotic $y^{+3}$-variation of SGS model [60].

The rate-of-strain tensor for the resolved scale $\bar{S}_{i j}$ and the subgrid-scale turbulent viscosity $\mu_{t}$ are modeled in the LES WALE model as [59]

$$
\begin{gathered}
\mu_{t}=\rho L_{s}^{2} \frac{\left(S_{i j}^{d} S_{i j}^{d}\right)^{3 / 2}}{\left(\bar{S}_{i j} \bar{S}_{i j}\right)^{5 / 2}+\left(S_{i j}^{d} S_{i j}^{d}\right)^{5 / 4}} \\
\bar{S}_{i j}=\frac{1}{2}\left(\frac{\partial \bar{u}_{i}}{\partial x_{j}}+\frac{\partial \bar{u}_{j}}{\partial x_{i}}\right) \\
S_{i j}^{d}=\frac{1}{2}\left(\bar{g}_{i j}^{2}+\bar{g}_{j i}^{2}\right)-\frac{1}{3} \delta_{i j} \bar{g}_{k k}^{2}, \bar{g}_{i j}=\frac{\partial \bar{u}_{i}}{\partial x_{j}}, L_{s}=\min \left(k d, C_{s} V^{1 / 3}\right)
\end{gathered}
$$

where $L_{s}$ is the mixing length for subgrid scale, $k$ is von Karman constant, $d$ is the distance to the closest wall, $V$ is the volume of the computational cell, and $C_{s}$ is the WALE constant and has the value of 0.5 based on the calibrations using freely decaying isotropic homogeneous turbulence [59].

2.3 Simulation Setup and Mesh. The governing equations were discretized in both space and time domains. The solution was based on the pressure-implicit with splitting of operators (PISO) algorithm for the pressure-velocity coupling. The centraldifference scheme was used for the diffusion terms in the governing equations. The pressure staggering option and quadratic upwind interpolation of convective kinematics (QUICK) scheme were employed for pressure and volume fraction discretization. The default momentum discretization scheme for LES, bounded central-differencing, was selected. The bounded centraldifferencing scheme can provide sufficiently low dissipation to allow the turbulent structures to evolve and enough robustness to handle highly stretched grids with large time-step [61]. To satisfy the total variation diminishing condition, the default limiter 
function which is derived from the work of Barth and Jespersen [62], was used.

The geometry of the cylindrical orifice in the present simulation is the same as that used by Stanley [16,17], as shown in Fig. 1. This orifice has a diameter of $8.25 \mathrm{~mm}$ and a contraction ratio of 6.06. The ratio of orifice length to orifice diameter $L / d$ is 4.85 . It should be noted that, like the orifice used in the experiment, the entrance of the orifice has a sharp edge, that is, there is not any rounding. In Stanley's experiment, the downstream side of the orifice was filled with nitrogen gas so that the outflow is a typical nonsubmerged jet. The present research focuses on the stage of partial cavitation within the orifice. To reduce computing cost, the downstream boundary was set at the exit of the orifice and the upstream boundary was set at $30 \mathrm{~mm}$ distance ahead of the orifice entrance. In the present simulation, the boundary conditions consisted of pressure inlet, pressure outlet, and no-slip walls. The ranges of operating parameters and some important dimensions of Stanley's experiment are shown in Table 1. Stanley pointed out that the changes of Re have very little effect on cavitation length behavior and shedding frequency variation [17]. On the premise of matching cavitation number, in order to make Re as close as possible to that of experimental conditions, the boundary conditions with a constant outlet pressure of $15235 \mathrm{~Pa}$ were carefully adjusted.

A steady RANS simulation result was used as the initial condition of LES, which can accelerate the convergence of LES. To accurately capture cavitation dynamics characteristics, the timestep of LES was set as $10^{-6} \mathrm{~s}$ which ensures an average Courant number less than 1.0. Within each time-step, 30 inner loops were set. The normalized residuals for each equation dropped by four orders of magnitude, and the critical variables such as the pressure at critical locations and the global volume of vapor were monitored. These ensure the convergence for each time-step [61]. The physical parameters of the working fluid were obtained from the National Institute of Standards and Technology (NIST) database [63]. The range/values of operating and physical parameters used in the simulation are listed in Table 2.

By using the meshing module ICEM, the $\mathrm{O}$ grid block was employed to discretize the computational domain. The computational domain and a typical mesh in the middle cut plane are shown in Fig. 2. The mesh was refined near the walls and the entrance. To resolve accurately turbulent eddies in the near-wall regions, the minimum cell size in the near orifice wall vicinity was set as $2 \mu \mathrm{m}$ to ensure that the nondimensional wall distance

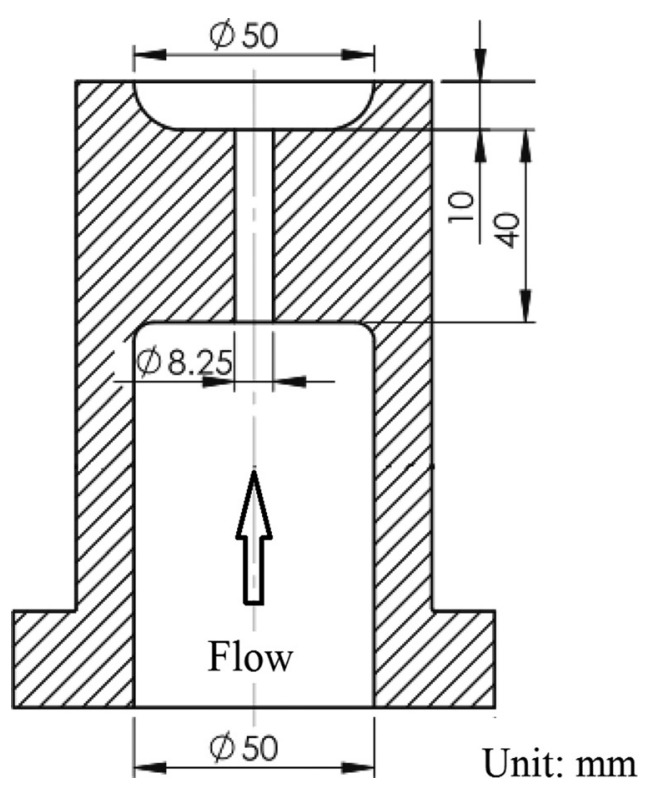

Fig. 1 The geometry of the cylindrical orifice used by Stanley $[16,17]$
Table 1 Summary of Stanley's experimental parameters [17]

\begin{tabular}{lc}
\hline \hline Parameter & value/range \\
\hline Nozzle orifice diameter, $d(\mathrm{~mm})$ & 8.25 \\
Nozzle orifice length, $L(\mathrm{~mm})$ & 40 \\
Supply pipe diameter, $D(\mathrm{~mm})$ & 50 \\
Reynolds number, $\mathrm{Re}=\frac{\rho V d}{\mu}$ & $7.4 \times 10^{4}-2.2 \times 10^{5}$ \\
Cavitation number, $\sigma=\frac{P_{1}-P_{v}}{P_{1}-P_{2}}$ & $1.1-3.6$ \\
\hline \hline
\end{tabular}

$y^{+}$is less than 1 . To determine an optimal grid resolution, the study of mesh influence was performed by monitoring the global vapor volume fraction $\alpha_{g}$ and the PSD of pressure fluctuations for the same near-wall monitoring point downstream of the cavitation region under the flow conditions of $P_{1}=151,500 \mathrm{~Pa}, \sigma=1.84$. It is helpful to evaluate the grid comprehensively by considering the global $\left(\alpha_{g}\right)$ and local (pressure fluctuation at monitoring point) measurement parameters simultaneously. According to Table 3, three grid resolutions were determined with a grid refinement ratio $r=1.3$ in all three directions. After two flow-through times, the data over another one flow-through time was collected. The flowthrough time was estimated by the length of the orifice and the average velocity. For $\sigma=1.84$, the cavitation shedding process and the global vapor volume fraction $\alpha_{g}$ exhibit periodicity. The evolution of global vapor volume fraction for three grid resolutions in three typical cycles is shown in Fig. 3. For each shedding process, the curves of global vapor volume fraction approach each other with a small difference as the mesh refines. The PSD distributions of pressure fluctuations are shown in Fig. 4. Three grid resolutions predicted close primary frequencies and similar spectral contents of the cavitation-induced pressure signals. It is observed that the pressure spectrum in the inertial subrange follows Kolmogorov's $-5 / 3$ theoretical power law [64]. This indicates that the present mesh and calculation are able to capture part of the turbulence spectrum. Furthermore, the range of the $-5 / 3$ power law for the fine and medium cases is slightly wider than that for the coarse case, which suggests that a finer grid may capture more turbulent kinetic energy [65]. It is known that the global vapor volume fraction $\alpha_{g}$ is periodic, and the fundamental frequency of $\operatorname{PSD} f_{b}$ for monitored pressure fluctuations is closely related to the cavitation shedding frequency $[2,31,43]$. The grid convergence index (GCI) $[66,67]$ of the time-averaged global vapor volume fraction $\overline{\alpha_{g}}$ and the fundamental frequency of PSD $f_{b}$ is introduced to estimate the uncertainty, as shown in Table 3. The uncertainty estimated by the GCI method has a value less than $5 \%$, which demonstrates that further refinement of meshes results in insignificant changes in the simulation outcome. Although further grid refinement may reveal more complex

Table 2 Summary of simulation parameters

\begin{tabular}{lc}
\hline \hline Parameter & value/range \\
\hline Nozzle orifice diameter, $d(\mathrm{~mm})$ & 8.25 \\
Nozzle orifice length, $L(\mathrm{~mm})$ & 40 \\
Supply pipe diameter, $D(\mathrm{~mm})$ & 50 \\
Reynolds number, $\mathrm{Re}=\frac{\rho V d}{\mu}$ & $6 \times 10^{4}-1.3 \times 10^{5}$ \\
Cavitation number, $\sigma=\frac{P_{1}-P_{v}}{P_{1}-P_{2}}$ & $1.38-3.1$ \\
Average flow velocity in orifice $(\mathrm{m} / \mathrm{s})$ & $7.6-18.5$ \\
Inlet pressure $P_{1}(\mathrm{~Pa})$ & $69,758-313,500^{\mathrm{a}}$ \\
Outlet pressure $P_{2}(\mathrm{~Pa})$ & $15,235^{\mathrm{a}}$ \\
Density $\rho_{l}($ liquid $)\left(\mathrm{kg} / \mathrm{m}^{3}\right)$ & 998.55 \\
Density $\rho_{v}($ vapor $)\left(\mathrm{kg} / \mathrm{m}^{3}\right)$ & $1.54 \times 10^{-2}$ \\
Viscosity $\mu_{l}($ liquid $)(\mathrm{Pa} \cdot \mathrm{s})$ & $1.05 \times 10^{-3}$ \\
Viscosity $\mu_{v}($ vapor $)(\mathrm{Pa} \cdot \mathrm{s})$ & $9.67 \times 10^{-6}$ \\
Vapor pressure $P_{v}(\mathrm{~Pa})$ & $2064.7^{\mathrm{b}}$ \\
\hline
\end{tabular}

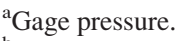

${ }^{\mathrm{b}}$ Absolute pressure. 


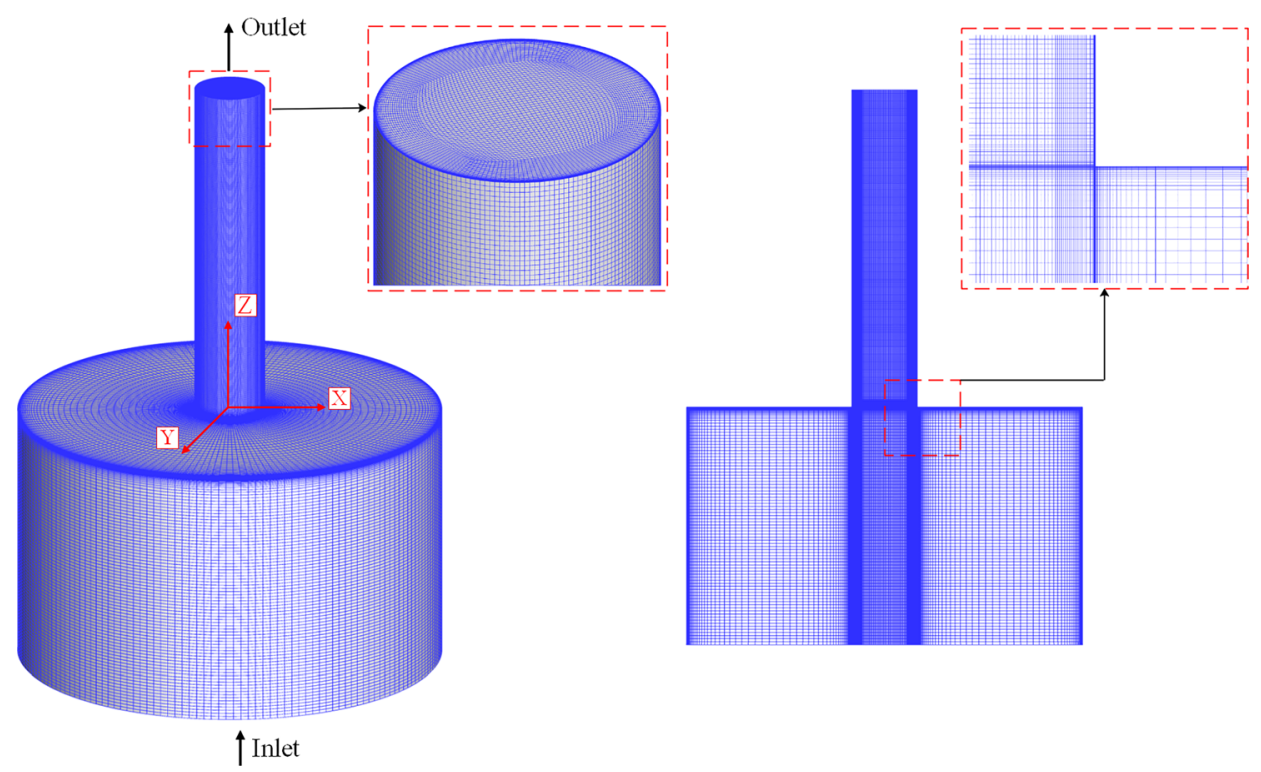

Fig. 2 The computational domain and a typical computational mesh

Table 3 Summary of mesh refinement study

\begin{tabular}{|c|c|c|c|c|c|c|c|c|c|}
\hline Mesh & Grid quantities & $\overline{\alpha_{g}}$ & $\mathrm{SD}^{\mathrm{a}}$ of $\alpha_{g}$ & $f_{b}(\mathrm{~Hz})$ & Determinant $3 \times 3 \times 3$ & Angle (deg) & Aspect ratio & Max ortho skew & Eriksson skew \\
\hline Coarse & $1.68 \times 10^{6}$ & $1.57 \times 10^{-3}$ & $1.31 \times 10^{-4}$ & 343 & $0.89-1$ & 24-90 & $1-153$ & 0.91 & $0.54-1$ \\
\hline Medium & $3.81 \times 10^{6}$ & $1.46 \times 10^{-3}$ & $1.26 \times 10^{-4}$ & 366 & $0.91-1$ & $30-90$ & $1-118$ & 0.79 & $0.55-1$ \\
\hline Fine & $8.58 \times 10^{6}$ & $1.43 \times 10^{-3}$ & $1.37 \times 10^{-4}$ & 377 & $0.93-1$ & $33-90$ & $1-91$ & 0.69 & $0.53-1$ \\
\hline GCI & & $0.98 \%$ & & $3.34 \%$ & & & & & \\
\hline
\end{tabular}

${ }^{\mathrm{a}}$ Standard deviation.

vortical structures and capture more turbulent kinetic energy, it is not the focus of the current research and it will lead to a substantial increase of the computational cost. Therefore, the mediumresolution mesh was selected as the final mesh in the following simulations. Figure 5 depicts the contours of wall $y^{+}$. It is observed that except for a small area in front of the sharp edge, the value of wall $y^{+}$for the orifice wall where cavitation initiates and develops is guaranteed to be less than 1. Due to the contraction effect, the velocity increases as the fluid enters the orifice. This makes that the value of wall $y^{+}$in the small area before the orifice entrance increases, but never exceeds 5. After the elapse of two flow-through times, the data over another one flow-through time was collected to evaluate the time-averaged normalized cavity length and the shedding characteristics. For each simulated

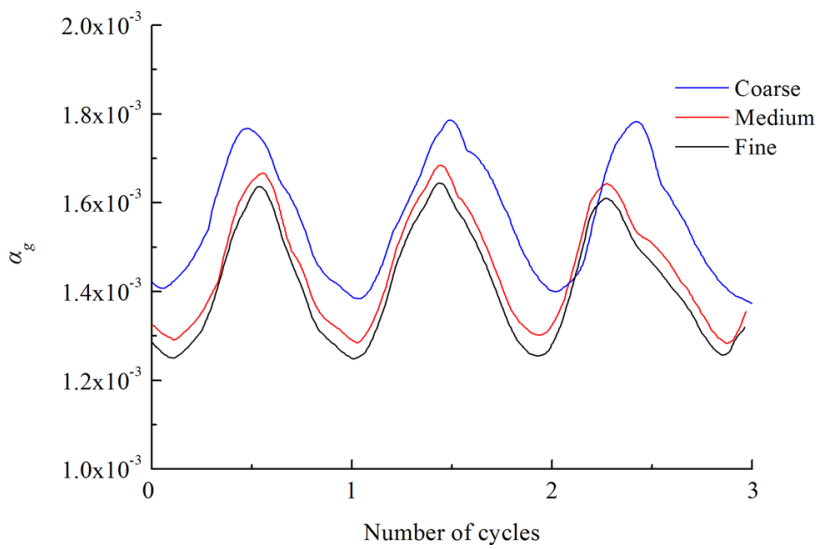

Fig. 3 The evolution of global vapor volume fraction for three grid resolutions in three typical cycles case, the computing time on an allocation of in-house cluster (144 processors, Intel Xeon Gold 6150, 384 GB RAM, Xi'an, China) is about 256000 CPU hours.

\section{Results and Discussions}

3.1 Cavity length and Cavitation Regimes. The cavity length is a significant parameter to identify cavitation regimes. For many hydraulic devices, cavitation patterns are often distinguished by the ratio of cavitation length to characteristic length.

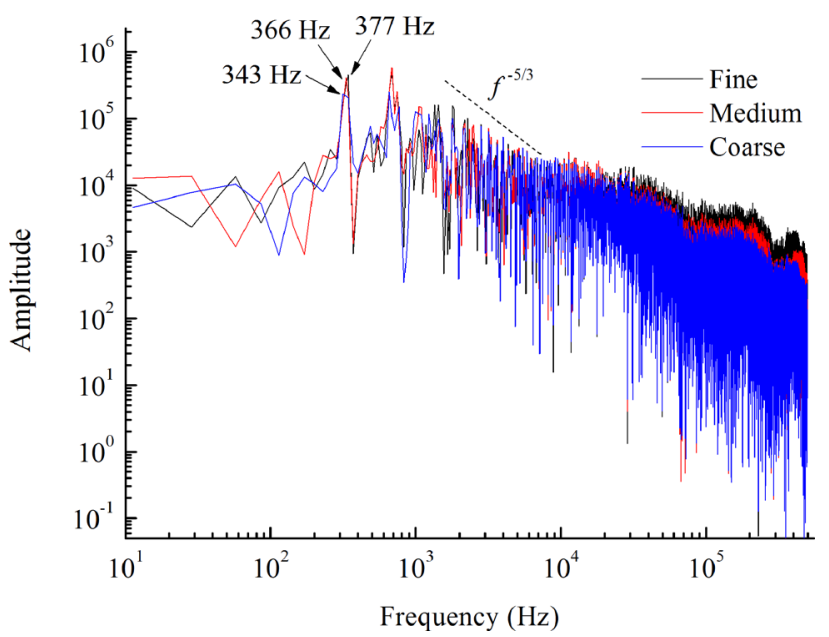

Fig. 4 The PSD distribution of pressure fluctuation for three grid resolutions 
For instance, in the case of an unsteady cavity on a hydrofoil, cavitation inception and supercavitation are characterized by a ratio of maximum cavity length to chord length equal to zero and one, respectively, between these is partial cavitation [32]. It is worth noting that for cavitation on a hydrofoil, supercavitation refers to the conditions in which the attached cavitation no longer closes on the wall but downstream of the trailing edge [32]. For a hydrofoil, the cavity length is usually referred to as the distance from the cavitation starting point near the leading edge to the location of cavity closure, that is, the length of the attached cavitation $L_{0}$. But for cavitating flow in an orifice, the cavity length is defined as the distance from the orifice entrance to the last point in the streamwise direction at which cavitation or bubbles can be identified [17] (as shown in Fig. 6(b)). A comparison of the timeaveraged cavity length $L_{\text {cav }}$ obtained from the present LES and RANS by Mouvanal et al. [68] with Stanley's experimental results is shown in Fig. 6(a). It should be noted that in Stanley's experiment, the total experimental uncertainty of $L_{\text {cav }} / L$ was up to $24 \%$ [17]. Meanwhile, the cavity length obtained with LES is affected by the value of vapor volume fraction. Therefore, the current research focus is not on the accurate value of cavity length, but on the ability of the numerical method to reproduce cavitation regimes by comparing the variation trend of cavitation length. In the present research, the cavity boundaries are identified with a reasonable value of $10 \%$ vapor volume fraction, which has been well adjusted and widely used [43,69].

The overall trend of time-averaged normalized cavity length for LES agrees qualitatively with the experimental data. As the cavitation number $\sigma$ decreases from 3.1 to 1.38 , the cavitation initiates within the separated shear layer near the orifice entrance and finally extends to the outlet. For different cavity lengths, five distinct cavitation patterns can be identified from the experimental (marked with squares) and LES simulation (marked with circles) results, respectively: A-supercavitation; B-developed cavitation; C-partial cavitation; D-incipient cavitation; E-single-phase flow. The typical cavitation images obtained from experimental visualization and LES are presented in Fig. 7. The cavitation structure of the simulation in Fig. 7 is isosurface plotted with a $10 \%$ volume fraction of vapor. It can be seen that incipient cavitation and partial cavitation are well reproduced by LES. Cavitation initiation, growth, and collapse are concentrated in a short distance near the entrance. Cavitation bubbles form sporadically around the nozzle entrance in the periphery of the separated boundary layer at the early stage of incipient cavitation. During partial cavitation, the sheet cavitation attached to the wall of the orifice is separated by a re-entrant jet to form cloud-like cavitation. This complex cyclical process will be discussed in detail in the following Sec. 3.2. For developed cavitation, it is an unstable transition region from partial cavitation to supercavitation; when $\sigma$ decreases slightly $L_{\text {cav }}$ increases significantly. In this stage, sporadical cavitation shedding rather than periodic cavitation shedding is observed. Further reduction of the cavitation number results in supercavitation. For orifice flows, supercavitation refers to the condition in which cavitation bubbles forming at the entrance extend along the entire length of the orifice and collapse at or beyond the exit [17]. As the cavitation number is reduced further, the attached cavity reaches the exit. In real experimental conditions, the ambient gas downstream, which has a relatively high pressure compared to the vapor region, flows backward and takes up the separation zone producing a jet that separates at the orifice entrance and remains detached from the orifice wall for the entire length of the orifice. This condition is referred to as a hydraulic flip, which usually requires the volume of fluid approach to consider the ambient gas $[68,70]$, and it is not the focus of our current research but the subject of future work.

Mouvanal et al. [68] simulated incipient cavitation until cavitation number $\sigma<1.9$ with the RANS method. According to their numerical results, periodic cavitation is delayed until the cavitation number is between 1.8 and 1.6, as shown in Fig. 6(a) with triangles. The periodic shedding process was reproduced, but the liquid re-entrant jet under the attached cavitation was not observed. With further reduction in cavitation number, the cavity length of the RANS simulation grows and reaches the exit of the orifice at around $\sigma=1.4$. From Fig. 6(a), it can be observed that compared with the RANS method, LES can better simulate the discontinuous increase of cavitation length as $\sigma$ decreases, and can more accurately identify the partial cavitation regime from the variation trend of cavitation length.

Note that there are some discrepancies between the LES simulation and experiment. During developed cavitation, the flocculent and filamentous cavitation in the middle of the orifice was not reproduced, as shown in Fig. 7( $\mathrm{g}$ ). This may be because some very small scales have not been fully resolved. The incipient cavitation region D identified by LES (bottom of Fig. 6(a)) is larger than that by experiment (top of Fig. 6(a)). This discrepancy may be due to the different accuracy of cavitation image acquisition between experiment and simulation. In Stanley's experiment, the cavitation region was measured by analyzing the backlit highspeed video recordings. Cavitation structures were identified by applying a grayscale threshold to the image, converting the image to binary data; white representing liquid, black representing vapor. A reasonable threshold value is crucial for the accurate identification of cavitation. To focus on the main cavitation structure, the threshold value might be set too high, this causing the neglect of some tiny cavitation. Furthermore, the imperfection of the boundary conditions and the models used may also be responsible for these deviations.

Sato and Saito [19] revealed similar trends in cavity length in experiments using water for various length-to-diameter ratios. Figure 8 shows the time-averaged normalized cavity length data from Stanley and Sato and Saito. In Stanley's experiment, the minimal scatter of the data indicates that the effects of changes of Re have very little effect on the cavity length behavior. All of the series, except Sato Exp-C with the shortest $L_{\text {cav }} / d$ ratio, demonstrate a discontinuous increase of cavitation length as the cavitation number reduces and crosses a certain value. This discontinuity in cavity length appears to be related to the position of the turbulent flow reattachment relative to the exit of the orifice [17].

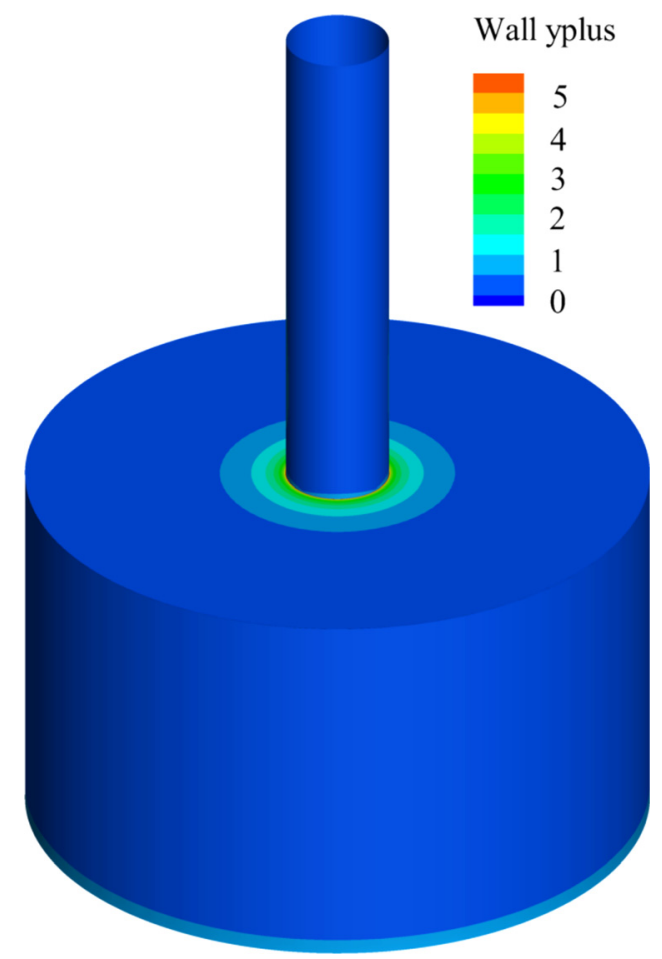

Fig. 5 The contours of wall $y^{+}$ 


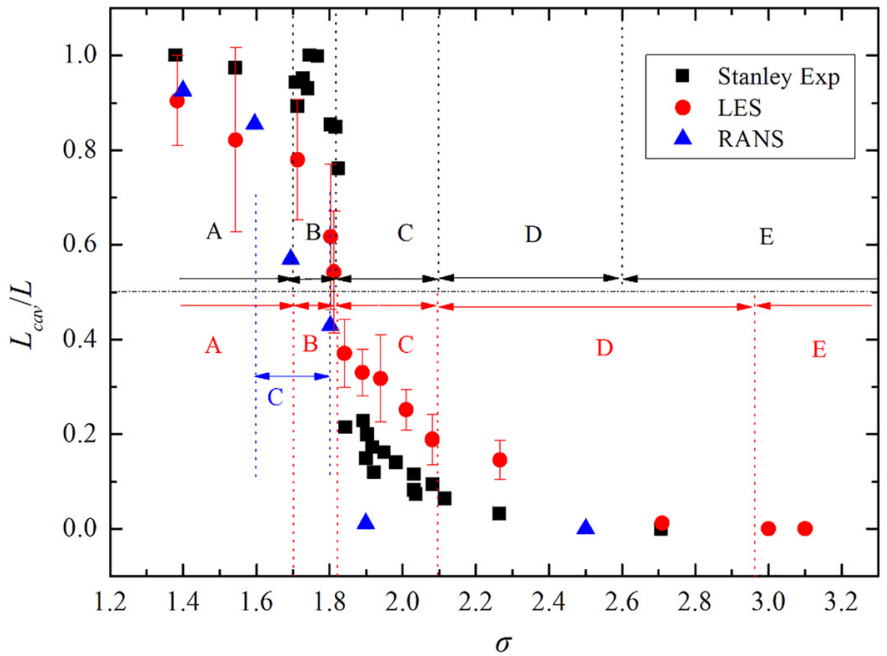

(a)

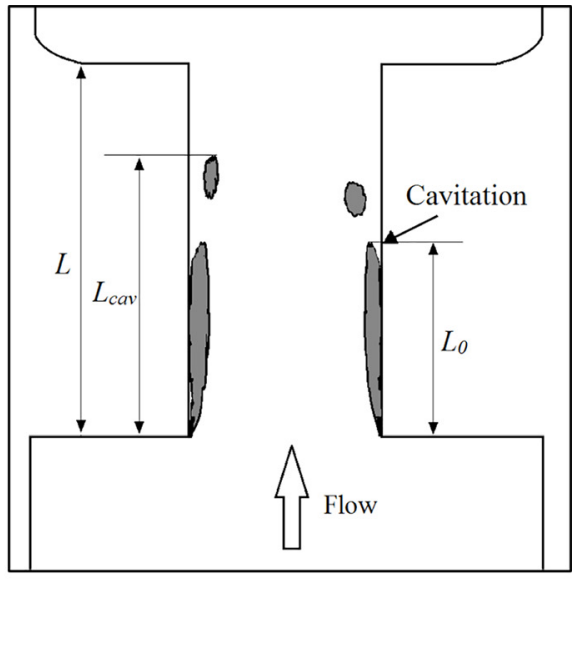

(b)

Fig. 6 (a) Time-averaged normalized cavity length from Stanley's experiment [17], LES, and RANS [68] and (b) schematic diagram of $L_{\text {cav }}$ and $L_{0}$

3.2 Re-Entrant Jet and Periodic Cavitation Shedding. The periodic shedding of the attached cavitation accompanied by the formation and collapse of cloud cavitation was observed for cavitation numbers between approximately $\sigma=1.84$ and $\sigma=2.1$ (region $\mathrm{C}$ in Fig. 6(a)). In order to display complete cavitation characteristics with time, the appropriate view regions on a symmetry plane of the fluid domain for contours of vapor volume fraction were selected as shown in Fig. 9. There are four pressure monitor points labeled $P_{+X}, P_{-X}, P_{+Y}$, and $P_{-Y}$ near the wall at the location of $z=30 \mathrm{~mm}$ where is the end of the shedding path. These points are arranged at equal angles in the circumferential direction to record pressure fluctuations in different directions. A typical sequence of cavitation shedding and collapse for $\sigma=1.84$ can be seen in Fig. 10. Images (a)-(p) correspond to the flow time $0.0265 \mathrm{~s}-0.031 \mathrm{~s}$ after two flow-through times with a time interval $\Delta t=300 \mu \mathrm{s}$. The experimental visualization images in Fig. 11 were taken by Stanley using a high-speed camera for $\sigma=1.80$. Basically, the images $1-15$ in Fig. 11 are corresponding to images (b)-(j) in the top half of Fig. 10. To demonstrate more details of the re-entrant jet motion, the sequence with a smaller time interval is shown in Fig. 12, including contours of vapor volume fraction and velocity vectors colored with pressure distribution.

We can observe the shedding process by comparing the top half of Figs. 10 and 11. Images (b) and 1 show attached cavitation labeled $\mathrm{A}$ which is attached to the entrance of the orifice, and cloud cavitation labeled B, which has been shed from the attached cavity. From images (a)-(d) and 1-4, it can be seen that the attached cavity continues to grow while the shed cloud cavitation is conveyed into the higher-pressure region and begins to collapse. The cloud cavitation collapse and resulting high-pressure zone can be seen clearly in Fig. 12 labeled D from $0.0272 \mathrm{~s}$ to $0.0274 \mathrm{~s}$. The separated shear flow from the vena contracta of the orifice reattaches at the point labeled E in Fig. 12. Under the action of the adverse pressure gradient (as shown in the region labeled $\mathrm{F}$ ) and the pressure pulses generated by cloud cavitation collapse, the liquid mass provided by reattachment is driven to form the so-called re-entrant jet. In a visualization test, the front surface of the reentrant jet labeled $\mathrm{G}$ can be discerned by the deformation of the vapor-liquid interface while in the simulation, it can be demonstrated by the distribution of the flow velocity. The reattachment

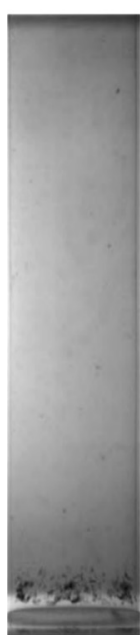

(a)

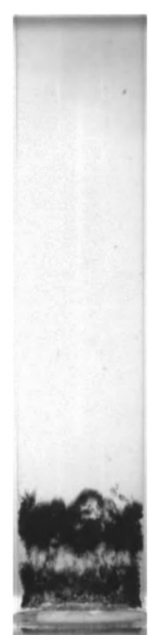

(b)

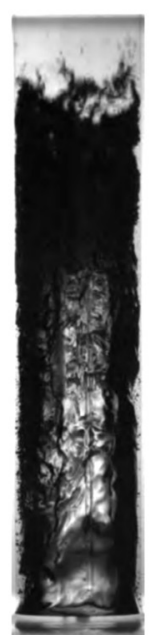

(c)

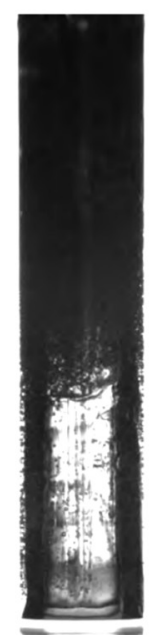

(d)

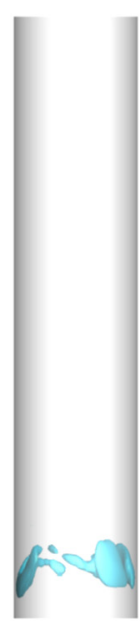

(e)

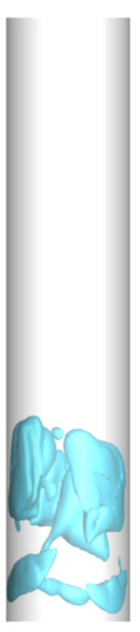

(f)

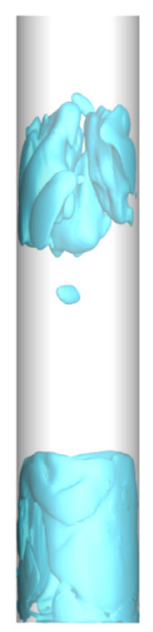

(g)

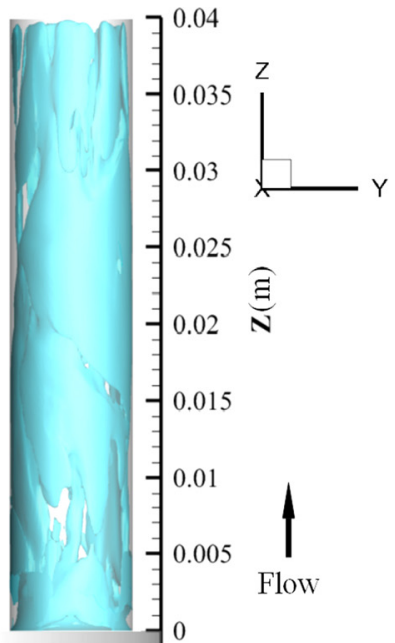

(h)

Fig. 7 Orifice cavitation structures, Stanley's experiment [17]: (a) incipient cavitation $(\sigma=2.27)$, (b) partial cavitation $(\sigma=1.93)$, (c) developed cavitation $(\sigma=1.76)$, (d) supercavitation $(\sigma=1.36)$; LES: $(e)$ incipient cavitation $(\sigma=2.27),(f)$ partial cavitation $(\sigma=1.94),(g)$ developed cavitation $(\sigma=1.8)$, and $(h)$ supercavitation $(\sigma=1.38)$ 


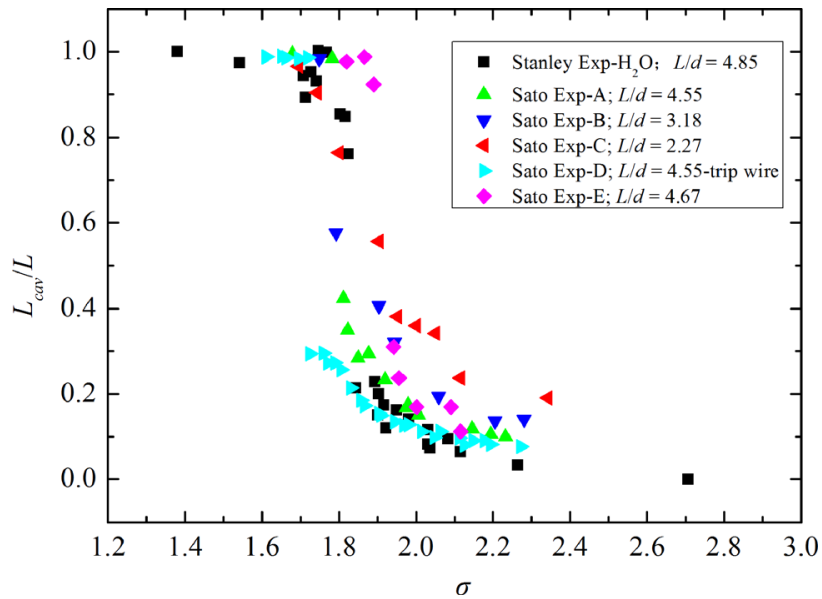

Fig. 8 Time-averaged normalized cavity length comparison. Data labeled $\mathrm{H}_{2} \mathrm{O}$ represent data from Ref. [17]. Data labeled series A-E are cavity length data for various orifice geometries adapted from Ref. [19].

continues to provide liquid flow, and the re-entrant jet beneath the attached cavity labeled $\mathrm{C}$ moves upstream until it reaches the orifice entrance. Eventually, the initial attached cavity labeled A is cut off and detached from the wall of the orifice to form the new cloud cavitation labeled $\mathrm{B}^{\prime}$, which can be seen in the images (c)-(f) of Fig. 10 and the images 5-11 of Fig. 11. Then a new attached cavity labeled $\mathrm{A}^{\prime}$ begins to form and grow. Meanwhile, the shed cloud cavitation, $\mathrm{B}^{\prime}$, moves downstream with the main flow, coalesces, and finally collapses, to initiate the next re-entrant jet and shedding process (as shown in images $(\mathrm{g})-(\mathrm{p})$ of Fig. 10). The images (j)-(p) are analogous to the images (a)-(f) in Fig. 10: the cavitation formation, growth, coalescence, shedding, and collapse repeat, indicating the periodicity of the process. The

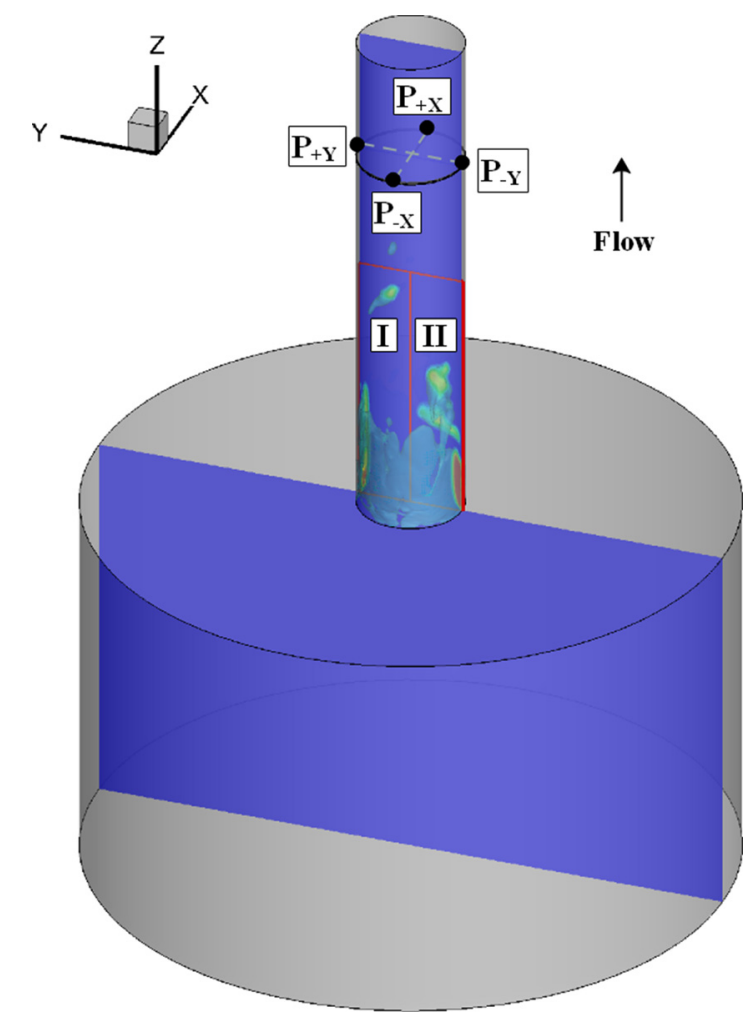

Fig. 9 Schematic illustrating view regions I and II and four pressure monitor points images (g) and (p) exhibit similar shedding characteristics. This indicates that the cycle period is about $2.7 \mathrm{~ms}$. By comparing the upper and lower parts of Fig. 10, it is easy to find that although both show a complete shedding process, including formation, growth, coalescence, shedding, and collapse, they are not synchronized. This phenomenon will be discussed in Sec. 3.3, where the determination of period and shedding frequency will be discussed in detail in Sec. 3.4.

3.3 Three-Dimensional Asymmetric Shedding Mode. For the flow around a symmetric structure such as cylinder, the asymmetry of cavitation and vortex shedding has been well reported. However, for the internal flow passing through a symmetric structure especially for solids of revolution, such as cylindrical orifice and venturi, there are very few studies about the asymmetry of cavitation shedding. Ahuja et al. [35] simulated the asymmetry of cloud cavitation shedding in a cylindrical orifice by hybrid RANS-LES. They speculated that this asymmetry may be responsible for flapping modes or azimuthal modes. As above mentioned, the periodic shedding processes in the view regions I and II are not synchronized. If we use the length of attached cavitation $L_{0}$ to represent the evolution of the cavitation shedding process, as shown in Fig. 13, we can see that there is a phase difference between the view regions I and II. A similar evolution of attached cavitation length in view region II can be obtained by making that in view region I about $1.3 \mathrm{~ms}$ earlier or about $1.4 \mathrm{~ms}$ later. The time period of the attached cavitation length variation estimated from Fig. 12 is about $2.7 \mathrm{~ms}$; in other words, the phase difference of the attached cavitation length variation between view regions I and II is about $\pi$.

The Stanley experiment also provided some evidence for the 3D asymmetric shedding in the orifice. Figure 14 shows a sequence of diagonal re-entrant jet motion observed by Stanley [17] for $\sigma=1.83$. The initial re-entrant jet identified by solid lines and arrows moves to the right and eventually arrives at the entrance. After that, a new one appears at the right and moves to the left. It seems that the re-entrant jet indicated in Fig. 11 moves toward the entrance of the orifice, but actually it has a circumferential velocity component. Stanley thought that the diagonal reentrant jet motion and the asymmetric shedding appeared to be initiated by the convection of large noncondensable gas bubbles through the orifice. These bubbles violently expanded and significantly altered the cavitation structure when they were conveyed into the low-pressure region at the entrance. This would cause the cavity closure line to be inclined relative to the direction of the oncoming flow. An inclined closure line forced the re-entrant jet to move along a diagonal rather than perpendicular to the entrance. This is similar to the three-dimensionality observed on hydrofoils $[33,34]$ : the component of oncoming velocity tangential to the closure line remains unchanged, while the component normal to the closure line is reflected (as shown in Fig. 15).

Figure 16 shows a 3D sequence of asymmetric cavitation shedding from LES for $\sigma=1.84$. During the periodic shedding process, one part of the attached cavitation labeled A, cloud cavitation labeled B and re-entrant jet motion labeled C, occupy the zones around view region I, while the other part occupies the zones around view region II. Accordingly, they are labeled A-I, B-I, C-I and A-II, B-II, C-II, respectively. The dotted line represents the boundary of A-II, although it is irregular and sometimes unclear. As shown in the image at $0.0272 \mathrm{~s}$, the attached cavitation zones A-I and A-II occupy each half of the orifice entrance. The cloud cavitation B-II has shed from A-II, while shed cloud cavitation B-I is moving downstream. Starting from image $0.0274 \mathrm{~s}$, the pressure pulses, generated by the collapse of cloud cavitation B-I, drive the liquid mass provided by reattachment to form re-entrant jet C-I which is identified by solid lines and arrows. The re-entrant jet C-I moves to the right and eventually severs A-I from the orifice entrance to form a new shed cavitation zone $\mathrm{B}^{\prime}$-I. Then, new attached cavitation $\mathrm{A}^{\prime}$-I begins to form and grow. Meanwhile, 


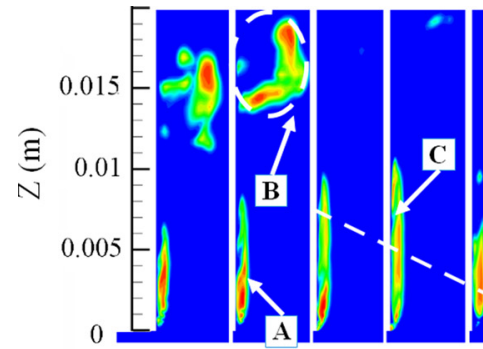

(a)

(b)

(c) (d)

(d) $\quad(e)$
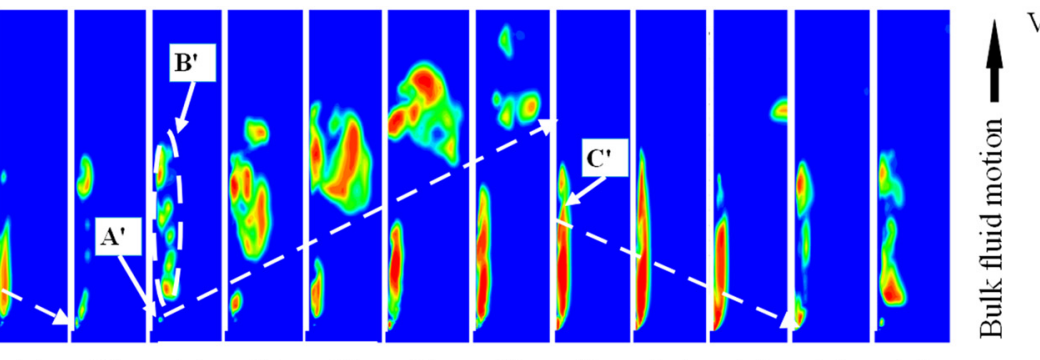

(g) (h)

(i) (j)

(k)

(I) $(m)$

(n)

(o)

(p)

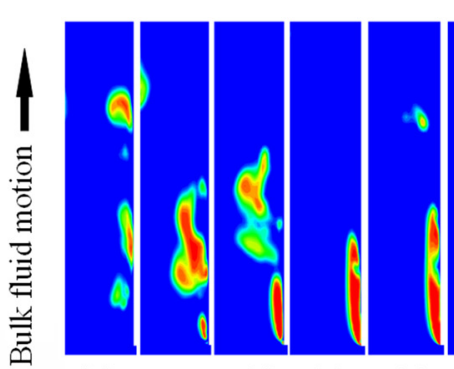

lew region I

(a)

(b)

(c) (d)

(e)
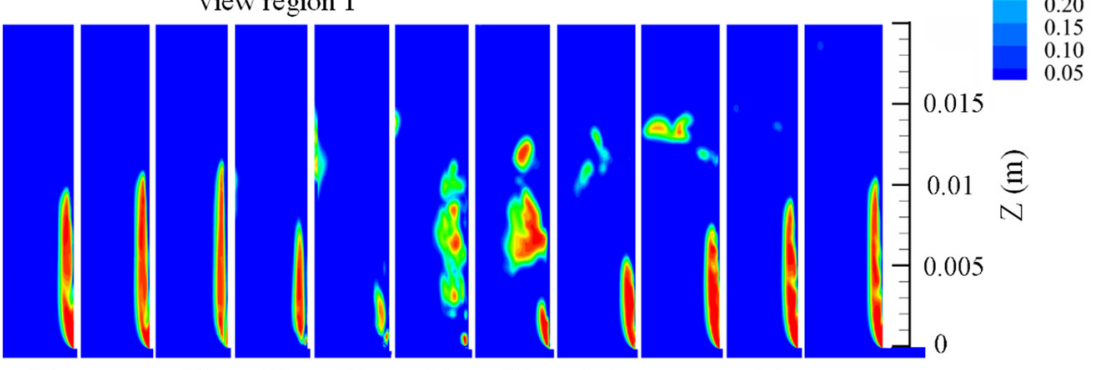

(g)

(h) (i)

(j)

(k)

(I)

(m)

(n)

(o)

(p)

Increasing time

Fig. 10 Cavitation shedding sequence from LES for $\sigma=1.84$, the time between images $\Delta t=300 \mu$ s. Annotations: A, B, and C identify the attached cavity, cloud cavitation, and re-entrant jet, respectively, where an apostrophe implies a newly formed structure.

B-II travels downstream where it collapses due to high pressure. The driven re-entrant jet C-II, which is also identified by solid lines and arrows moves to the left and eventually severs A-II from the orifice entrance to form a new shed cavitation B'-II. Accordingly, a new attached cavitation $\mathrm{A}^{\prime}$-II begins to form and grow. The new shed cavitation $\mathrm{B}^{\prime}$-I continues to move downstream, collapses, and drives a new re-entrant jet $\mathrm{C}^{\prime}$-I. From a threedimensional point of view, it seems that both the re-entrant jet and the attached cavitation around the view region I converge toward this plane. The re-entrant jet motion and shedding processes in part I and part II repeat periodically, but they are not synchronized. The phase difference of the shedding process between part I and part II is about $\pi$, similar to the variation of attached cavitation length as estimated from Fig. 13. Although the boundary between zones I and II is not clear enough, the shedding processes within both sides seem to be partitioned by the symmetric plane of view regions I and II ( $Z-X$ plane), with little influence on each other. It is worth noting that the re-entrant jet motions C-I and CII travel diagonally relative to the oncoming velocity. This is a $3 \mathrm{D}$ effect due to the inclination of the closure line, similar to Stanley's observation shown in Fig. 14. Compared to the 2D sequence in Fig. 10, the 3D image sequence shown in Fig. 16 reveals more details about the asymmetric shedding process. But the common point of 2D and 3D sequences confirms the asymmetry of the cavitation shedding process and the out-of-phase mode of alternate shedding.

3.4 The Determination of Shedding Frequencies. As observed in Figs. 10, 11, and 16, if we define the moment when the re-entrant jet starts to move upstream as the beginning of a cycle, the re-entrant jet reaches the orifice entrance at about onethird of the period. After that, a new attached cavity forms and grows, accompanied by shed cavitation being advected

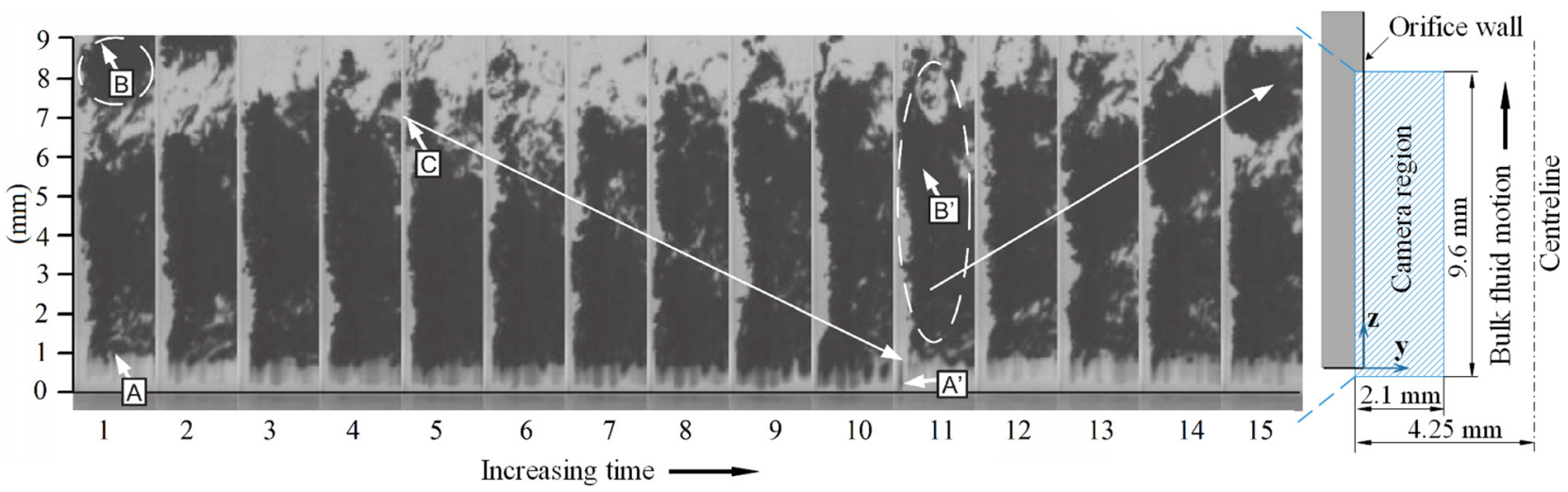

Fig. 11 Cavitation shedding sequence from Stanley's experiment for $\sigma=1.80$ [17], the time between images $\Delta t=110 \mu \mathrm{s}$. Annotations: A, B, and C identify the attached cavity, bubble cloud, and re-entrant jet, respectively, where an apostrophe implies a newly formed structure. 

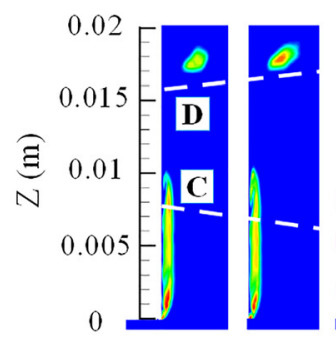

$0.0272 \mathrm{~s}$

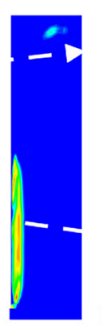

$0.0274 \mathrm{~s}$

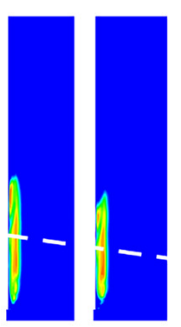

$0.0276 \mathrm{~s}$
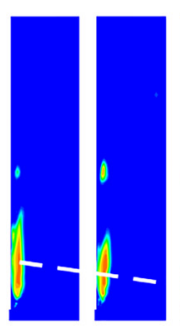

$0.0278 \mathrm{~s}$

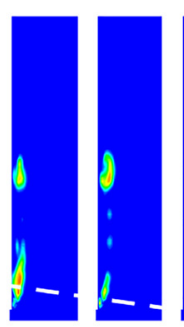

$0.028 \mathrm{~s}$

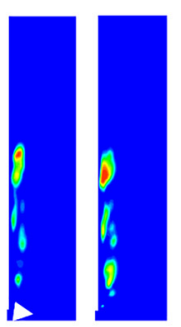

0.0282

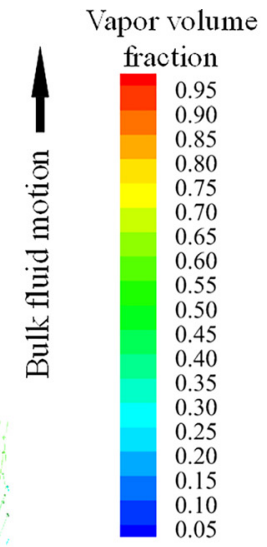

Pressure

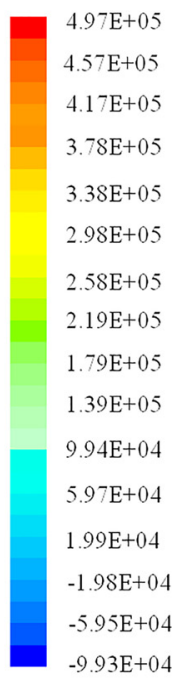

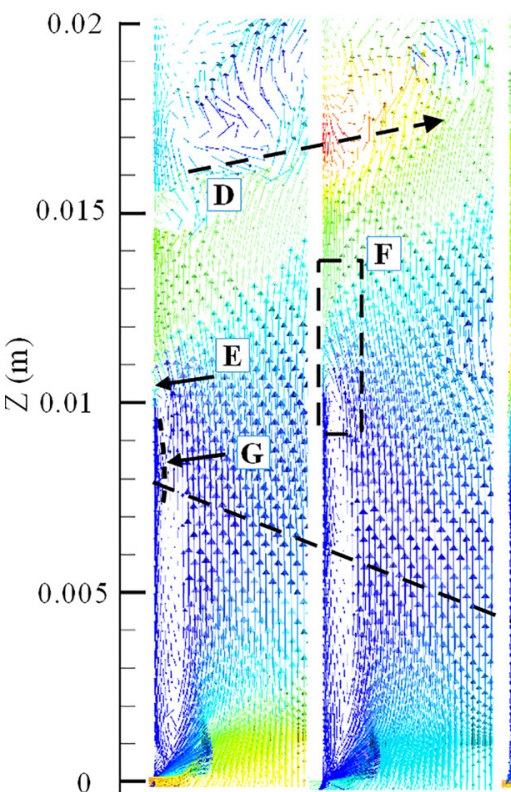

$0.0272 \mathrm{~s}$

$0.0274 \mathrm{~s}$

\begin{abstract}
$0.0276 \mathrm{~s}$
\end{abstract}

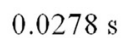

$0.0278 \mathrm{~s}$

$0.028 \mathrm{~s}$

View region I

Increasing time

Fig. 12 Re-entrant jet motion in Fig. (10). Annotations: C-re-entrant jet motion; D-cloud cavitation collapse and resulting high pressure; E-the reattached point of separated shear flow; F-the adverse pressure gradient; G-the front surface of the re-entrant jet.

downstream during the remaining two-thirds of the period. This phenomenon is similar to that of venturi and hydrofoil $[25,32]$. The difference is that for hydrofoils, the attached cavity keeps an almost constant length during the re-entrant jet motion in the first

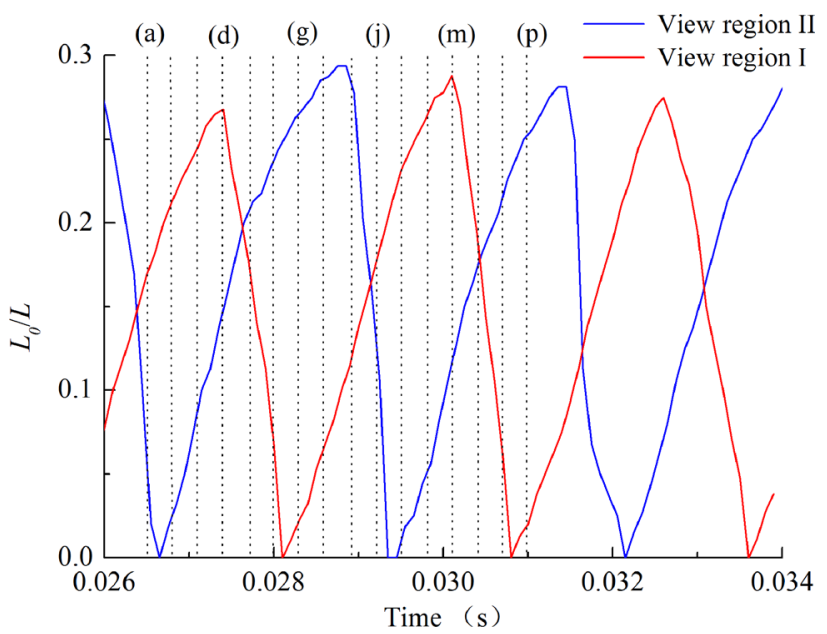

Fig. 13 The length variation of the attached cavitation for view regions I and II in Fig. (10) one-third of the period. Even in Stanley's record for $\sigma=1.80$ as shown in Fig. 10, it is consistent with that. But for the present simulation for $\sigma=1.84$, as shown in Figs. 12 and 13, as the re-entrant jet moves upstream, the length of attached cavitation decreases. This might be due to the insufficient thickness of the tail of the attached cavity, which results in the re-entrant jet disturbing the tail as it moves upstream.Under the condition of $\sigma=1.84$, there are about 36 shedding cycles in one flow-through time. For both view regions, the velocity of re-entrant motion $U_{r}$ and the growing velocity of attached cavity $U_{a}$ within each shedding cycle can be estimated from the linear fitting of the re-entrant jet motion labeled $\mathrm{C}$ in Fig. 12 and the variation of attached cavitation length in Fig. 13, respectively $[17,19]$. The average velocities $\overline{U_{r}}$ and $\overline{U_{a}}$ during 36 shedding cycles are estimated and shown in Table 4. For each shedding cycle, the time period $T$ from the start of the re-entrant jet to the end of growth of the attached cavity can be estimated from [19]

$$
T=\frac{L_{0-\max }}{U_{r}}+\frac{L_{0-\max }}{U_{a}}
$$

where $L_{0 \text {-max }}$ is the maximum of attached cavity length at the end of cavity growth, as shown in Fig. 13.

As discussed previously, the period $T$ of the cloud cavitation shedding process appears to be correlated to the time for the reentrant jet to cover the maximum of attached cavity length $L_{O \text {-max }}$. The average velocity $U$ in the orifice is $12 \mathrm{~m} / \mathrm{s}$ according to the 

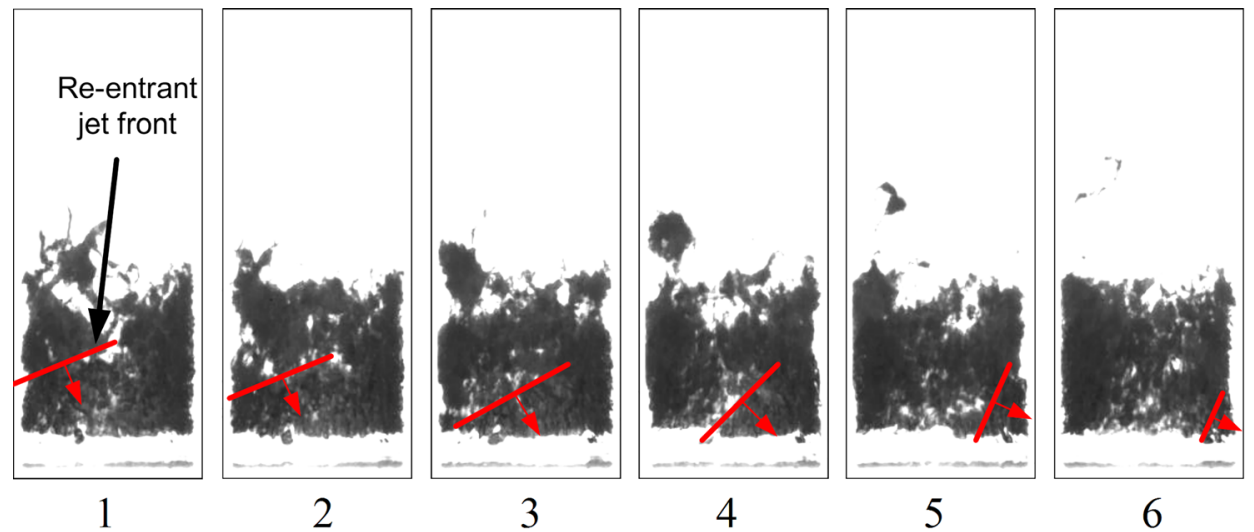

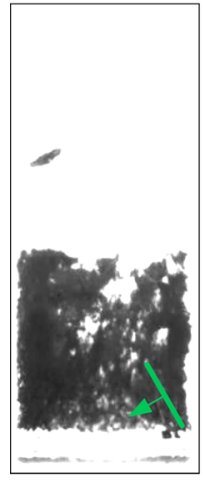

7

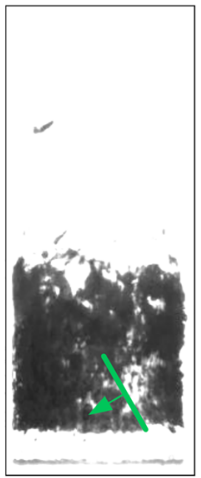

8

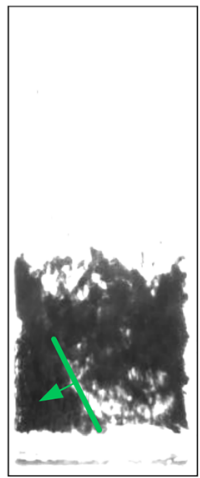

9

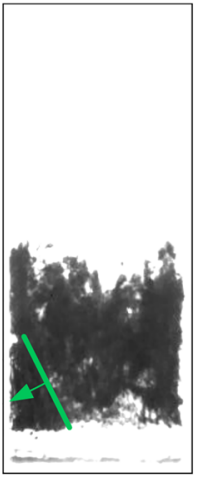

10

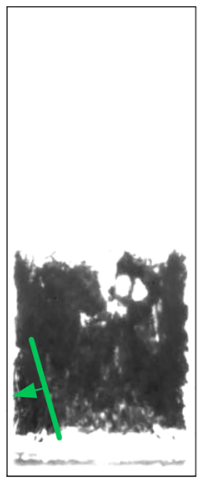

11

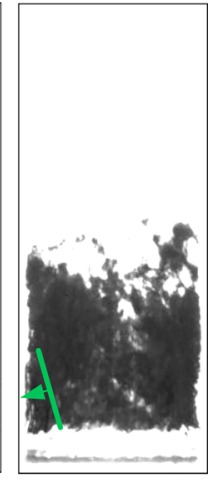

12

Fig. 14 Image sequence showing the asymmetric motion of re-entrant jets for $\sigma=1.83$ with the time between images $\Delta t \approx 130 \mu \mathrm{s}$, which is from Stanley's experiment [17]

volume flow rate obtained from the steady flow simulations. Since the re-entrant jet velocity is of the order of the flow velocity $U$, this time is of the order of $L_{0 \text {-max }} / U$. Within each shedding cycle, the Strouhal number $S_{t}$ is defined as the ratio of this characteristic time to the period of shedding [32]:

$$
S_{t}=\frac{\frac{L_{0-\text { max }}}{U}}{T}=f \frac{L_{0-\text { max }}}{U}
$$

where $f$ is the shedding frequency, $f=1 / T$.

Substituting Eq. (21) into Eq. (22)

$$
S_{t}=\frac{1}{\frac{U}{U_{r}}+\frac{U}{U_{a}}}
$$

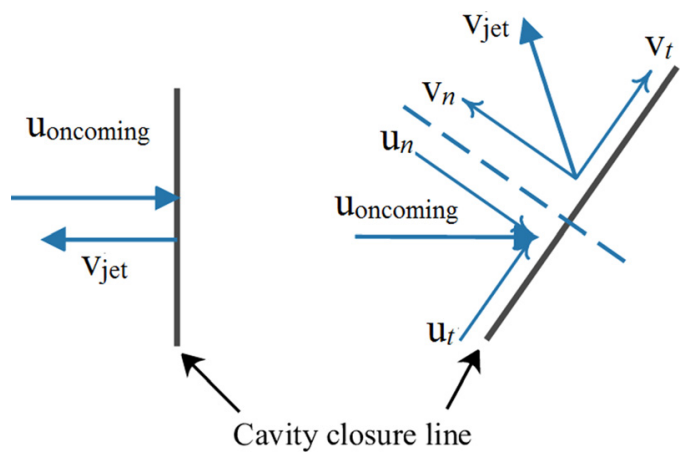

Fig. 15 Reflection of oncoming flow by the closure line of the cavity [33]
According to the Eqs. (21) and (23), for $\sigma=1.84$, the average shedding time period $\bar{T}$ and frequency $\bar{f}$ as well as Strouhal number $\overline{S_{t}}$ during 36 shedding cycles can be estimated, as shown in Table 4. It can be found that the values of the average time period $\bar{T}$ are slightly larger than those estimated from the shedding sequence and the variation of the attached cavity length. This discrepancy is mainly because in the current simulation results, the re-entrant jet starts before the attached cavitation length reaches its maximum, as shown in images (c) and (1) of the top half of Fig. 10. Due to the large uncertainty in the determination of cavity length, the Strouhal number usually has a non-negligible dispersion characteristic and lies in the range $0.25-0.35$ [32]. The average Strouhal number for $\sigma=1.84$ can be estimated as 0.31 and 0.30 , which agrees well with the typical value of 0.30 . This also means that the time of the re-entrant jet motion is about $30 \%$ of the shedding period, which agrees with the observation from the shedding process and the variation of the attached cavity length.

Another common method to evaluate the shedding frequency is monitoring the pressure fluctuation during the cavitation shedding process. To record the pressure fluctuation, we set four monitor points, as shown in Fig. 9. Figures 17 and 18 show the time evolution of pressure fluctuation and the corresponding PSD calculated with the Welch method [71] for $\sigma=1.84$. In the evolution process of cavitation, we can see that the pressure fluctuation at the four monitor points has very similar trends, notably that they have almost the same abrupt pressure peaks including major peaks and minor peaks. The near synchronization of pressure fluctuation peaks at different positions can also be observed in the simulation of cavitation shedding on hydrofoils, and these pressure peaks were identified as corresponding to the collapse of the shed cloud cavitation [43]. For orifice cavitation, referring to the shedding process shown in Figs. 10 and 16, we find that the major pressure peaks correspond to the cloud cavitation collapse around view 

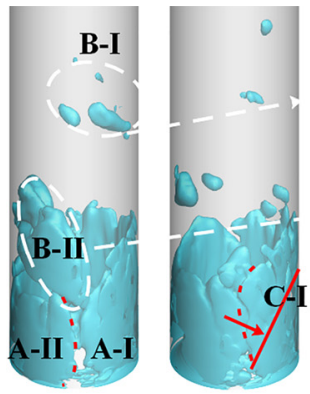

$0.0272 \mathrm{~s}$

$0.0274 \mathrm{~s}$

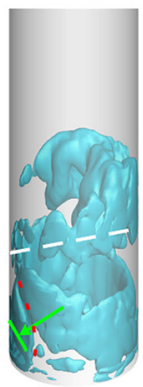

$0.0288 \mathrm{~s}$

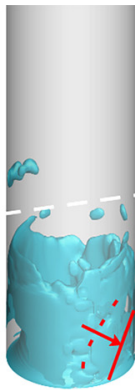

$0.0276 \mathrm{~s}$

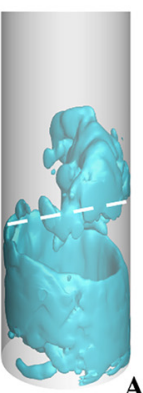

$0.0292 \mathrm{~s}$

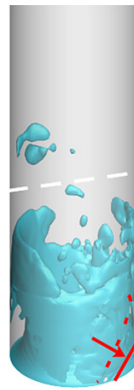

$0.0278 \mathrm{~s}$

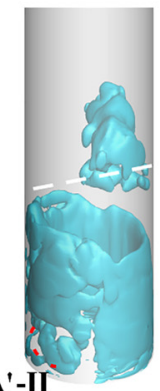

$0.0294 \mathrm{~s}$

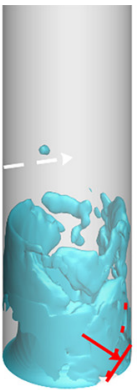

$0.028 \mathrm{~s}$

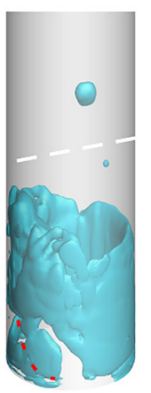

$0.0296 \mathrm{~s}$

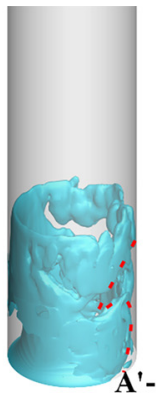

$0.0282 \mathrm{~s}$

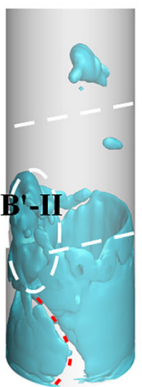

$0.0298 \mathrm{~s}$

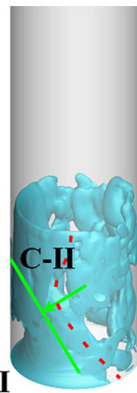

$0.0284 \mathrm{~s}$

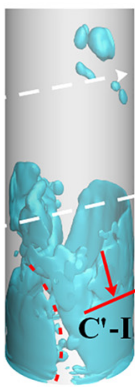

$0.03 \mathrm{~s}$
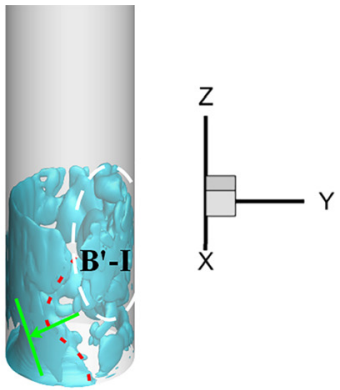

$0.0286 \mathrm{~s}$

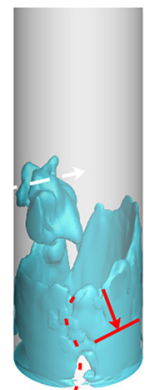

$0.0302 \mathrm{~s}$

Fig. 16 Image sequence showing 3D asymmetry of cavitation shedding from LES for $\sigma=1.84$, the time between images $\Delta t=200 \mu \mathrm{s}$. Annotations: A, B, and C identify the attached cavity, cloud cavitation, and re-entrant jet, respectively, where I and II denote the parts of view regions I and II, and an apostrophe implies a new structure

Table 4 Summary of shedding frequency estimation

\begin{tabular}{|c|c|c|c|c|c|c|c|c|c|c|c|}
\hline \multirow[b]{2}{*}{ View region } & \multicolumn{2}{|c|}{$U_{r}(\mathrm{~m} / \mathrm{s})$} & \multicolumn{2}{|c|}{$U_{a}(\mathrm{~m} / \mathrm{s})$} & \multicolumn{2}{|c|}{$L_{0-\max }(\mathrm{mm})$} & \multicolumn{2}{|c|}{$T(\mathrm{~ms})$} & \multirow[b]{2}{*}{$\bar{f}(\mathrm{~Hz})$} & \multicolumn{2}{|c|}{$S_{t}$} \\
\hline & $\overline{U_{r}}$ & $\mathrm{SD}^{\mathrm{a}}$ & $\overline{U_{a}}$ & $\mathrm{SD}^{\mathrm{a}}$ & $\overline{L_{0-\max }}$ & $\mathrm{SD}^{\mathrm{a}}$ & $\bar{T}$ & $\mathrm{SD}^{\mathrm{a}}$ & & $\overline{S_{t}}$ & $\mathrm{SD}^{\mathrm{a}}$ \\
\hline I & 10.4 & 1.1 & 5.9 & 0.4 & 11.1 & 1.7 & 2.9 & 0.28 & 345 & 0.31 & 0.02 \\
\hline II & 9.9 & 1.6 & 5.7 & 0.5 & 11.3 & 1.8 & 3.1 & 0.31 & 323 & 0.30 & 0.03 \\
\hline
\end{tabular}

${ }^{\mathrm{a}}$ Standard deviation.

region I, while the minor pressure peaks correspond to the cloud cavitation collapse around view region II. For instance, the major peaks 1 and 2 are caused by the collapse of B-I (image (c) of view region $\mathrm{I}$ in the top half of Fig. 10 and image $0.0272 \mathrm{~s}$ in Fig. 16) and $B^{\prime}-$ I (image (1) of view region $I$ in the top half of Fig. 10 and image $0.0296 \mathrm{~s}$ in Fig. 16), respectively. The minor peaks 1 and 2 are caused by the collapse of zones B-II (images (d) of view region II in the bottom half of Fig. 10 and images $0.0274 \mathrm{~s}$ in

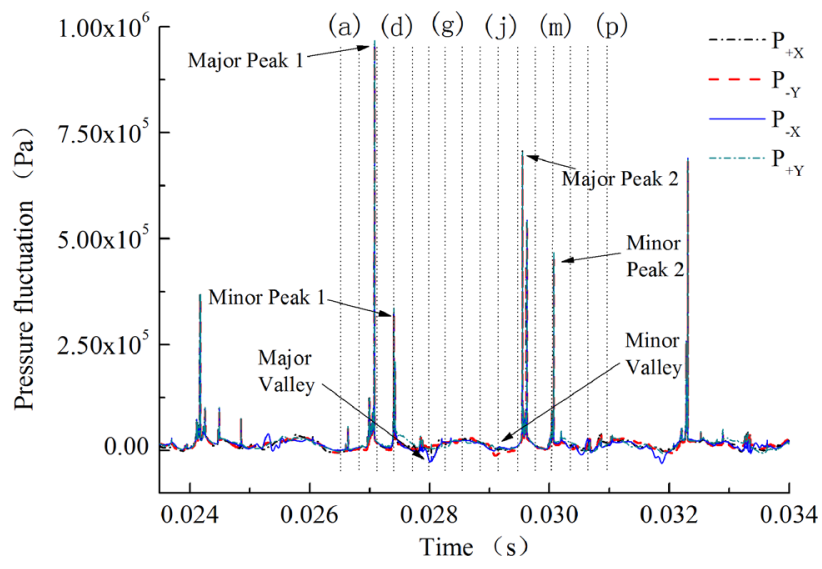

Fig. 17 Time evolution of pressure fluctuation for $\sigma=1.84$
Fig. 16) and $\mathrm{B}^{\prime}$-II (images (m) of view region II in the bottom half of Fig. 10 and images $0.0302 \mathrm{~s}$ in Fig. 16), respectively. It can be observed that after the major and minor peaks, there are some very small pressure peaks caused by the continuous collapse of small bubbles. There are also some pressure valleys including major valleys and minor valleys. The major pressure valley

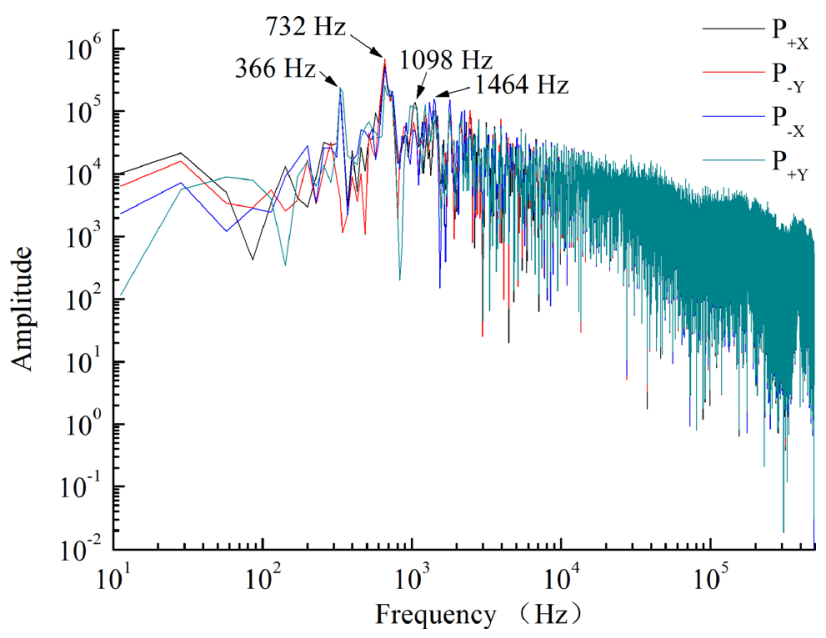

Fig. 18 The PSD of pressure fluctuation for $\sigma=1.84$ 
corresponds to the initial attached cavitation being severed and the shedding process around view region I (images (f) of view region I in the top half of Fig. 10, and images $0.028 \mathrm{~s}$ in Fig. 16). The minor pressure valley corresponds to a similar process around view region II (images (j) of view region II in the bottom half of Fig. 10, and images $0.0292 \mathrm{~s}$ in Fig. 16). These correspondences indicate that the attached cavitation being severed and shedding induces a pressure decrease to form a pressure valley, while the collapse of shed cavitation causes the abrupt pressure peak. This statement is consistent with the cloud cavitation shedding process in a rectangular orifice studied by $\mathrm{He}$ et al. [2]. However, due to the $3 \mathrm{D}$ asymmetric flow characteristics in a cylindrical orifice, the present situation is more complex. Although both sides show a complete shedding process, the amount of shed cavitation for the right (zone I) is more than that for the left (zone II), as shown in Fig. 16. This explains why the collapse of B-I causes a major pressure peak while the collapse of B-II causes a minor pressure peak.

As mentioned above, if we define the moment when the reentrant jet starts to move upstream as the beginning, a cycle goes about from images (c) to (k) in Fig. 10, including one major pressure peak, one minor pressure peak, and one major and one minor pressure valley. This composition is repeated in other cycles of pressure fluctuation.

Generally, the PSD for four monitor points shown in Fig. 18 has a similar distribution below the cutoff frequency of $5 \times 10^{5}$ $\mathrm{Hz}$. The main frequency peaks are concentrated in the range of about 200-20000 Hz. Obviously, the fundamental frequency of $366 \mathrm{~Hz}$ with second, third, and fourth harmonics can be identified. All of the monitor points except $P_{-Y}$ present frequency peaks at the fundamental frequency $366 \mathrm{~Hz}$, although their amplitudes are slightly smaller than that of the second harmonic $732 \mathrm{~Hz}$. As mentioned above, the shedding period estimated by the variation of attached cavity length or the frame-frame variation of the shedding process is about $2.7 \mathrm{~ms}$. The corresponding shedding frequency can be calculated as about $370 \mathrm{~Hz}$, which is almost equal to the fundamental frequency of the pressure PSD. The shedding frequency of $345 \mathrm{~Hz}$ and $323 \mathrm{~Hz}$ calculated by Eq. (21) in Table 4, is also close to the fundamental frequency. Note that the shedding processes of both sides run simultaneously with a phase difference of about $\pi$. Therefore, it can be concluded that the fundamental frequency of pressure PSD corresponds to the unilateral shedding frequency of asymmetrical shedding, while the second harmonic frequency $732 \mathrm{~Hz}$ corresponds to the combined shedding frequency for both sides.

In the present incompressible formulation, the speed of sound tends to infinity. The reflectional pressure wave that might be

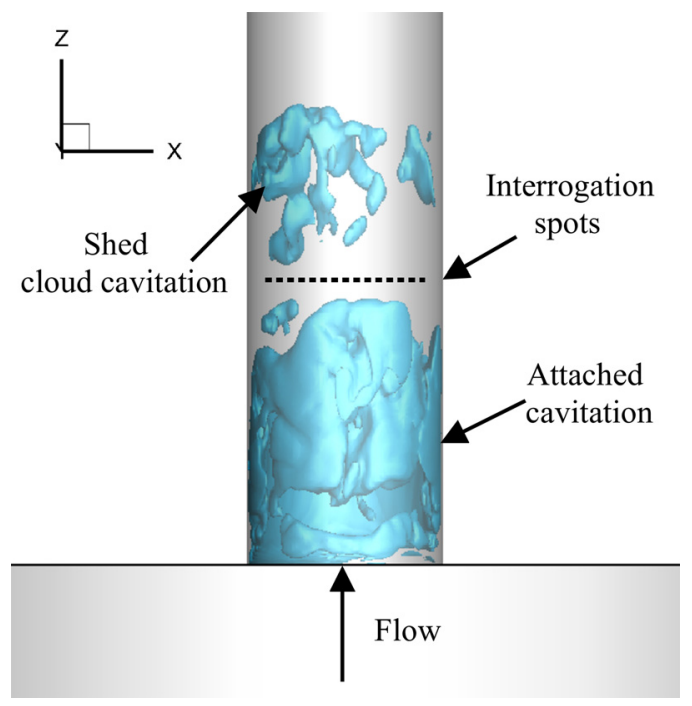

Fig. 19 Schematic of interrogation spots used for cavitation frequency analysis in Stanley's experiment [17] generated at the exit appears almost simultaneously with the original pressure wave generated by the cavity collapse event. Therefore, for incompressible cavitating flow simulation, it is usually not necessary to employ buffer zones or nonreflecting boundary conditions $[41,42,72]$ to avoid the interference of reflection waves to the spectral content as is the case in the simulation of compressible cavitating flow [73].

In Stanley's experiment, the author selected a streamwise location in the collapse region where the shed cloud regularly passed but which was not a location permanently occupied by the attached cavity. The interrogation spots spaced evenly across the width of the nozzle were placed in the streamwise position [17], as shown in Fig. 19. The grayscale signal for chosen interrogation spots was extracted from the image sequence and analyzed using a MATLAB program. The shedding frequency was determined by calculating the PSD of the grayscale signal with the Welch method [71]. In the case of asymmetrical shedding with phase difference $\pi$, shed cavitation of both sides would pass through the interrogation spots alternately with a time difference of half a period. As a consequence, the shedding frequency estimated by the Stanley method is actually a combined shedding frequency for alternate shedding of both sides, which is two times higher and thus corresponds to the second harmonic frequency of pressure PSD.

Figure 20 shows the shedding frequency variation as the cavitation number increases for Stanley's experiment and the present LES. For $\sigma$ greater than 1.94, due to the thinner attached cavity, the simulated asymmetric shedding process is not regular enough. However, their PSD of pressure fluctuation shows a similar distribution as $\sigma=1.84$ with obvious fundamental frequency as well as second, third, and fourth harmonics. Thus, the shedding frequency for LES is estimated by the PSD of pressure fluctuation, where $f_{b}$ represents the fundamental frequency. For better comparison with experimental data, each fundamental frequency is multiplied by a factor of two. The scatter of experimental data represents the uncertainty of cavitating flow. For $\sigma=1.84$ and 1.89 , twice the fundamental frequency is very close to the shedding frequency measured by Stanley. With cavitation number increasing, except for $\sigma=1.94$, the $2 f_{b}$ of pressure PSD fall in the range of the measured shedding frequency. This confirms the above judgment and indicates that the shedding frequency measured by the Stanley method should be divided by two to obtain the unilateral shedding frequency. The shedding frequency shows an approximate linear trend of increasing frequency with increasing cavitation number for both experiment and simulation. The increasing trend predicted by LES is slightly less than that in the experiment. This may be due to the simplification of boundary conditions and the imperfection of the model used.

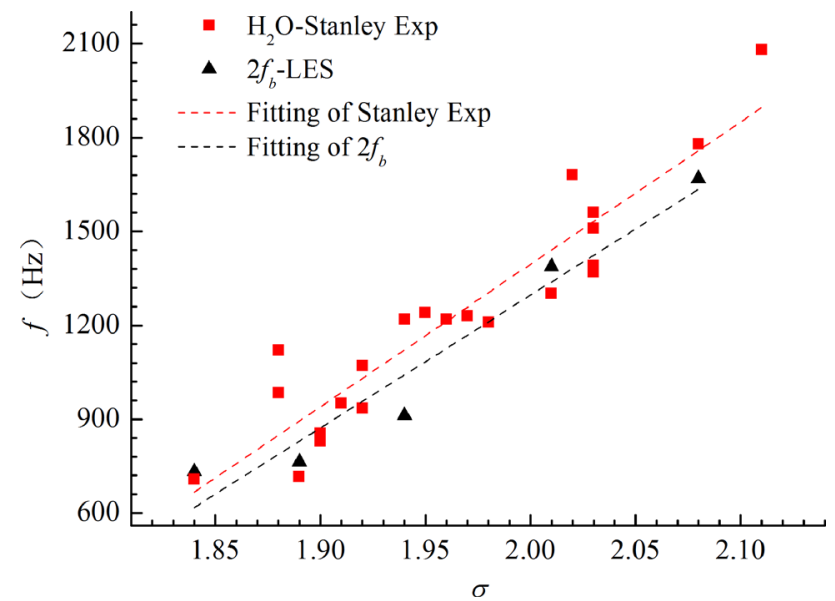

Fig. 20 The shedding frequency as a function of cavitation number increase 


\section{Conclusions}

In this paper, the cavitation regime transition and periodic shedding process during partial cavitation in a long cylindrical orifice used by Stanley in his experiment have been simulated with LES. The re-entrant jet and 3D asymmetric shedding mode, as well as the determination of the shedding frequency, were analyzed. Based on this study, the following conclusions can be drawn:

(1) As the cavitation number $\sigma$ decreases, the cavitation regime in a long cylindrical orifice starts from incipient cavitation, then goes through partial cavitation, developed cavitation, and supercavitation. This transition is accompanied by an increase in the cavitation length $L_{\text {cav }}$ from zero to the length of the orifice $L$. Compared with the RANS method, the LES can more accurately identify the partial cavitation regime.

(2) Two $2 \mathrm{D}$ view regions in the symmetry plane of the orifice with specific azimuth reveal two complete but unsynchronized periodic shedding processes. Within each shedding process, the countercurrent motion of the re-entrant jet driven by the pressure wave generated by the collapse of cloud cavitation finally severs the original attached cavitation to form new cloud cavitation. Then a new attached cavitation begins to grow accompanied by the downstream moving of the new cloud cavitation. The simulated re-entrant jet and shedding mechanism agree well with the visualization observations.

(3) The variation of the attached cavitation length for two view regions indicates that the phase difference between the two periodic shedding processes is about $\pi$. The $3 \mathrm{D}$ shedding process is similar to that seen in the $2 \mathrm{D}$ view regions, but more details, especially on the three-dimensionality caused by the inclination of the cavitation closure line, are revealed. The inclined closure line leads the re-entrant jet to move along a diagonal rather than perpendicular to the entrance of the orifice. Based on the 3D shedding process analysis, the three-dimensional asymmetric shedding mode with phase difference $\pi$ is revealed.

(4) A complete shedding cycle at both sides of the cylindrical orifice is defined by the re-entrant jet motion (approximately one-third of the cycle) and attached cavitation growth accompanied by cloud cavitation moving downstream until it collapses (approximately two-thirds of the cycle). By estimating the average velocity in the orifice, the growth velocity of attached cavitation, and the moving velocity of a re-entrant jet from simulation results, the average shedding frequency $\bar{f}$ and Strouhal number $\overline{S_{t}}$ are estimated for both sides. It is found that the unilateral shedding frequency corresponds to the fundamental frequency of PSD of simulated fluctuating pressure. The calculated shedding frequencies are consistent with Stanley's [17] experimental results.

\section{Acknowledgment}

We thank Ph.D. Fang Xing-Jun of the University of Manitoba for his kind help on the mesh refinement study. Thanks are also due to Ph.D. Wang Changchang of Beijing Institute of Technology for her beneficial suggestions.

\section{Funding Data}

- National Natural Science Foundation of China (Nos. 51876150 and 21736008; Funder ID: 10.13039/501100001809).

- Doctoral Visiting Program of China Scholarship Council (CSC) (No. 201606280288; Funder ID: 10.13039/501100004543).

\section{Nomenclature}

$d=$ orifice diameter

$D=$ diameter of the orifice supply pipe

$f=$ shedding frequency of cloud cavitation $f_{b}=$ fundamental frequency of PSD for pressure fluctuation

$\bar{f}=$ average shedding frequency of cloud cavitation

$L=$ orifice length

$L_{\mathrm{cav}}=$ cavitation length

$L_{0}=$ attached cavitation length

$L_{0-\max }=$ the maximum of attached cavity length

$R_{B}=$ bubble radius

$S=$ net mass source term

$S_{c}=$ condensation source term

$S_{e}=$ evaporation source term

$S_{t}=$ Strouhal number based on attached cavitation length $L_{0}$

$\overline{S_{t}}=$ average Strouhal number based on attached cavitation length $L_{O}$

$T=$ time period of cloud cavitation shedding

$\bar{T}=$ average time period of cloud cavitation shedding

$U=$ average velocity in the orifice

$U_{a}=$ growing velocity of the attached cavity

$\overline{U_{a}}=$ average growing velocity of the attached cavity

$U_{r}=$ velocity of re-entrant motion

$\overline{U_{r}}=$ average velocity of re-entrant motion

$\mathbf{V}_{v}=$ velocity vector of the gaseous phase

$y^{+}=$nondimensional wall distance

\section{Greek Symbols}

$\alpha=$ vapor volume fraction per volume of liquid

$\alpha_{g}=$ global vapor volume fraction

$\overline{\alpha_{g}}=$ time-average global vapor volume fraction

$\mu=$ viscosity

$\mu_{l}=$ liquid viscosity

$\mu_{v}=$ vapor viscosity

$\rho=$ mixture density

$\rho_{v}=$ vapor density

$\rho_{l}=$ liquid density

$\sigma=$ cavitation number

\section{References}

[1] Sun, Z., Li, G., Chen, C., Yu, Y., and Gao, G., 2015, "Numerical Investigation on Effects of Nozzle's Geometric Parameters on the Flow and the Cavitation Characteristics Within Injector's Nozzle for a High-Pressure Common-Rail DI Diesel Engine," Energy Convers. Manage., 89, pp. 843-861.

[2] He, Z., Chen, Y., Leng, X., Wang, Q., and Guo, G., 2016, "Experimental Visualization and LES Investigations on Cloud Cavitation Shedding in a Rectangular Nozzle Orifice," Int. Commun. Heat Mass Transfer, 76, pp. 108-116.

[3] Trummler, T., Schmidt, S. J., and Adams, N. A., 2020, "Investigation of Condensation Shocks and Re-Entrant Jet Dynamics in a Cavitating Nozzle Flow by Large-Eddy Simulation,” Int. J. Multiphase Flow, 125, p. 103215.

[4] Tamaki, N., Shimizu, M., and Hiroyasu, H., 2001, "Enhancement of the Atomization of a Liquid Jet by Cavitation in a Nozzle Hole," Atom. Spray, 11, pp. $125-137$.

[5] Hiroyasu, H., 2000, "Spray Breakup Mechanism From the Hole-Type Nozzle and Its Applications," Atom. Spray, 10(3-5), pp. 511-527.

[6] Sanmiguel-Rojas, E., Gutierrez-Castillo, P., del Pino, C., and Auñón-Hidalgo, J. A., 2019, "Cavitation in Transient Flows Through a Micro-Nozzle," ASME J. Fluids Eng., 141(9), p. 091107.

[7] Payri, F., Bermudez, V., Payri, R., and Salvador, F. J., 2004, "The Influence of Cavitation on the Internal Flow and the Spray Characteristics in Diesel Injection Nozzles," Fuel, 83(4-5), pp. 419-431.

[8] Payri, R., Garcia, J., Salvador, F., and Gimeno, J., 2005, “Using Spray Momentum Flux Measurements to Understand the Influence of Diesel Nozzle Geometry on Spray Characteristics," Fuel, 84(5), pp. 551-561.

[9] Asi, O., 2006, "Failure of a Diesel Engine Injector Nozzle by Cavitation Damage," Eng. Fail Anal., 13(7), pp. 1126-1133.

[10] Gavaises, M., Papoulias, D., Andriotis, A., Giannadakis, E., and Theodorakakos, A., 2007, "Link Between Cavitation Development and Erosiondamage in Diesel Fuel Injector Nozzles," SAE Paper No. 2007-01-0246.

[11] Gavaises, M., 2008, "Flow in Valve Covered Orifice Nozzles With Cylindrical and Tapered Holes and Link to Cavitation Erosion and Engine Exhaust Emissions," Int. J. Eng. Res., 9(6), pp. 435-447.

[12] Khojasteh-Manesh, M., and Miralam, M., 2019, "Evaluation of Cavitation Erosion Intensity in a Microscale Nozzle Using Eulerian-Lagrangian Bubble Dynamic Simulation," ASME J. Fluids Eng., 141(6), p. 061303.

[13] Roosen, P., Unruh, O., and Behmann, M., 1996, "Untersuchung Und Modelierung Des Transienten Verhaltens Von Kavitationserscheinungen Bei Ein- Und Mehrkomponentigen Kraftstoffen in Schnell Durchstromten Dusen," Institute for Technical Thermodynamics, RWTH Aachen (Univ. of Tech.), Germany (in German), Internal Report. 
[14] Winklhofer, E., Philipp, H., Hirsch, A., and Morozov, A., 2000, "Cavitation and Spray Formation in Diesel Flow Situations," Proceedings of the ILASSEurope Conference, Darmstadt, Germany, Sept. 11-13, pp. I71-I76.

[15] Winklhofer, E., Kull, E., Kelz, E., and Morozov, A., 2001, "Comprehensive Hydraulic and Flow Field Documentation in Model Throttle Experiments Under Cavitation Conditions," Proceedings of the ILASS-Europe Conference, Zurich, Sept. 2-6, pp. 574-579.

[16] Stanley, C., Barber, T., Milton, B., and Rosengarten, G., 2011, "Periodic Cavitation Shedding in a Cylindrical Orifice," Exp. Fluids, 51(5), pp. 1189-1200.

[17] Stanley, C., 2012, "Experimental Investigation of Cavitation in a Cylindrical Orifice," Ph.D. thesis. University of New South Wales, Sydney, Australia.

[18] Soteriou, C., Andrews, R., and Smith, M., 1995, "Direct Injection Diesel Sprays and the Effect of Cavitation and Hydraulic Flip on Atomization," SAE Paper No. 950080 .

[19] Sato, K., and Saito, Y., 2002, "Unstable Cavitation Behavior in a CircularCylindrical Orifice Flow," JSME Int. J., Ser. B, 45(3), pp. 638-645.

[20] Sugimoto, Y., and Sato, K., 2009, "Visualization of Unsteady Behavior of Cavitation in Circular Cylindrical Orifice With Abruptly Expanding Part [a]," Proceedings of the 13th International Topical Meeting on Nuclear Reactor Thermal Hydraulics, Kanazawa, Japan, Sept. 27-Oct. 2, Paper No. N13P1156.

[21] Sou, A., Hosokawa, S., and Tomiyama, A., 2010, "Cavitation in Nozzles of Plain Orifice Atomizers With Various Length-to-Diameter Ratios," Atom. Spray, 20(6), pp. 513-524.

[22] Nurick, W. H., 1976, "Orifice Cavitation and Its Effect on Spray Mixing," ASME J. Fluids Eng., 98(4), pp. 681-687.

[23] De Giorgi, M. G., Ficarella, A., and Tarantino, M., 2013, "Evaluating Cavitation Regimes in an Internal Orifice at Different Temperatures Using Frequency Analysis and Visualization," Int. J. Heat Fluid Flow, 39, pp. 160-172.

[24] Mitroglou, N., Stamboliyski, V., Karathanassis, I. K., Nikas, K. S., and Gavaises, M., 2017, "Cloud Cavitation Vortex Shedding Inside an Injector Nozzle," Exp. Therm. Fluid Sci., 84, pp. 179-189.

[25] Le, Q., Franc, J. P., and Michel, J. M., 1993, "Partial Cavities: Global Behavio and Mean Pressure Distribution,” ASME J. Fluids Eng., 115(2), pp. 243-248.

[26] Kawanami, Y., Kato, H., Yamaguchi, H., Tanimura, M., and Tagaya, Y., 1997, "Mechanism and Control of Cloud Cavitation," ASME J. Fluids Eng., 119(4), pp. 788-795.

[27] Callenaere, M., Franc, J. P., Michel, J. M., and Riondet, M., 2001, "The Cavitation Instability Induced by the Development of a Re-Entrant Jet," J. Fluid Mech., 444, pp. 223-256.

[28] Ganesh, H., 2015, "Bubbly Shock Propagation as a Cause of Sheet to Cloud Transition of Partial Cavitation and Stationary Cavitation Bubbles Forming on a Delta Wing Vortex," Ph.D. thesis, University of Michigan, Ann Arbor, MI.

[29] Ganesh, H., Mäkiharju, S. A., and Ceccio, S. L., 2016, "Bubbly Shock Propagation as a Mechanism for Sheet-to-Cloud Transition of Partial Cavities," J. Fluid Mech., 802, pp. 37-78.

[30] Jahangir, S., Hogendoorn, W., and Poelma, C., 2018, "Dynamics of Partial Cavitation in an Axisymmetric Converging-Diverging Nozzle," Int. J. Multiphase Flow, 106, pp. 34-45.

[31] Charrière, B., and Goncalves, E., 2017, " "Numerical Investigation of Periodic Cavitation Shedding in a Venturi," Int. J. Heat Fluid Flow, 64, pp. 41-54.

[32] Franc, J. P., and Michel, J. M., 2005, Fundamentals of Cavitation, Springer Science \& Business Media, Dordrecht, The Netherlands.

[33] De Lange, D. F., and De Bruin, G. J., 1997, "Sheet Cavitation and Cloud Cavitation, Re-Entrant Jet and Three-Dimensionality," Appl. Sci. Res., 58(1/4), pp. 91-114.

[34] Duttweiler, M. E., and Brennen, C. E., 1998, "Partial Cavity Instabilities," Proceedings of US-Japan Seminar: Abnormal Flow Phenomen in Turbomachines, Osaka, Japan, Nov. 1-6, Paper No. DUT18b.

[35] Ahuja, V., Hosangadi, A., Hitt, M. A., and Lineberry, D. M., 2013, "Numerical Simulations of Instabilities in Single-Hole Orifice Elements," AIAA Paper No. 2013-4058.

[36] Willian, H., 2017, "Experimental Investigation of Cavitation Regimes in a Converging-Diverging Nozzle," Master dissertation, Delft University of Technology, Delft, The Netherlands.

[37] Aeschlimann, V., Barre, S., and Djeridi, H., 2013, "Unsteady Cavitation Analysis Using Phase Averaging and Conditional Approaches in a 2D Venturi," Open J. Fluid Dyn, 03(03), pp. 171-183.

[38] Strasser, W., 2020, "The War on Liquids: Disintegration and Reaction by Enhanced Pulsed Blasting," Chem. Eng. Sci., 216, p. 115458.

[39] Strasser, W., and Battaglia, F., 2017, "The Effects of Pulsation and Retraction on non-Newtonian Flows in Three-Stream Injector Atomization Systems," Chem. Eng. J., 309(1), pp. 532-544.

[40] Strasser, W., and Battaglia, F., 2016, "Identification of Pulsation Mechanism in a Transonic Three-Stream Airblast Injector," ASME J. Fluids Eng., 138(11), p. 111303.

[41] Gnanaskandan, A., and Mahesh, K., 2016, "Large Eddy Simulation of the Transition From Sheet to Cloud Cavitation Over a Wedge," Int. J. Multiphase Flow, 83, pp. 86-102.

[42] Bhatt, M., and Mahesh, K., 2020, "Numerical Investigation of Partial Cavitation Regimes Over a Wedge Using Large Eddy Simulation," Int. J. Multiphase Flow, 122, p. 103155.

[43] Ji, B., Luo, X., Arndt Roger, E. A., Peng, X., and Wu, Y., 2015, "Large Eddy Simulation and Theoretical Investigations of the Transient Cavitating Vortical Flow Structure Around a NACA66 Hydrofoil," Int. J. Multiphase Flow, 68, pp. $121-134$

[44] Long, Y., Long, X., Ji, B., and Xing, T., 2019, "Verification and Validation of Large Eddy Simulation of Attached Cavitating Flow Around a Clark-Y Hydrofoil," Int. J. Multiphase Flow, 115, pp. 93-107.
[45] Ducoin, A., Huang, B. A., and Young, Y. L., 2012, "Numerical Modeling of Unsteady Cavitating Flows Around a Stationary Hydrofoil," Int. J. Rotating Mach. Artic. ID, 2012, pp. 1-17.

[46] Frikha, S., Coutier-Delgosha, O., and Astolfi, J. A., 2008, "Influence of the Cavitation Model on the Simulation of Cloud Cavitation on 2D Foil Section," Int. J. Rotating Mach, 2008, pp. 1-12.

[47] Charrière, B., Decaix, J., and Goncalves, E., 2015, "A Comparative Study of Cavitation Models in a Venturi Flow," Eur. J. Mech./B Fluids, 49, pp. 287-297.

[48] Morgut, M., Nobile, E., and Bilus, I., 2011, "Comparison of Mass Transfer Models for the Numerical Prediction of Sheet Cavitation Around a Hydrofoil,' Int. J. Multiphase Flow, 37(6), pp. 620-626.

[49] Martynov, S. B., Mason, D. J., and Heikal, M. R., 2006, "Modelling of Cavitation Flow in a Nozzle and Its Effect on Spray Development," Proceedings of the 13th International Heat Transfer Conference, Begell House, Sydney, Australia, Aug. 13-18, Paper No. JET-08.

[50] Mouvanal, S., Chatterjee, D., Bakshi, S., Burkhardt, A., and Mohr, V., 2018 "Numerical Prediction of Potential Cavitation Erosion in Fuel Injectors," Int. J. Multiphase Flow, 104, pp. 113-124.

[51] Bai, W., Duan, Q., and Zhang, Z., 2016 "Numerical Investigation on Cavitation Within Letdown Orifice of PWR Nuclear Power Plant," Nucl. Eng. Des., 305, pp. $230-245$.

[52] ANSYS, 2016, "ANSYS FLUENT Tutorial Guide 17.0," ANSYS, Inc., Canonsburg, PA

[53] Sun, Z., Li, G., Yu, Y., Gao, S., and Gao, G., 2015, "Numerical Investigation on Transient Flow and Cavitation Characteristic Within Nozzle During the Oil Drainage Process for a High-Pressure Common-Rail DI Diesel Engine," Energy Convers. Manage., 98, pp. 507-517.

[54] Mohan, B., Yang, W. M., and Chou, S. K., 2014, "Development of an Accurate Cavitation Coupled Spray Model for Diesel Engine Simulation," Energy Convers. Manage., 77, pp. 269-277.

[55] ANSYS, 2016, "ANSYS FLUENT Theory Guide 17.0," ANSYS, Inc., Canonsburg, PA.

[56] Schnerr, G., and Sauer, J., 2001, "Physical and Numerical Modeling of Unsteady Cavitation Dynamics," Proceedings of Fourth International Conference on Multiphase Flow, New Orleans, LA, May 27-June 1.

[57] Yuan, W., Sauer, J., and Schnerr, G. H., 2001, "Modelling and Computation of Unsteady Cavitation Flows in Injection Nozzles," Mech. Ind., 2, pp. 383-394.

[58] Brennen, C. E., 1995, Cavitation and Bubble Dynamics, Oxford University Press, Oxford, UK

[59] Nicoud, F., and Ducros, F., 1999, "Subgrid-Scale Stress Modelling Based on the Square of the Velocity Gradient Tensor," Flow Turbul. Combust., 62(3), pp. $183-200$

[60] Luo, X., Ji, B., Peng, X., Xu, H., and Nishi, M., 2012, "Numerical Simulation of Cavity Shedding From a Three-Dimensional Twisted Hydrofoil and Induced Pressure Fluctuation by Large Eddy Simulation,” ASME J. Fluids Eng., 134(4), p. 041202 .

[61] ANSYS, 2016, “ANSYS FLUENT Users Guide 17.0,” ANSYS, Inc., Canonsburg, PA.

[62] Barth, T. J., and Jesperson, D. C., 1989, "The Design and Application of Upwind Schemes on Unstructured Meshes," AIAA Paper No. 89-0366.

[63] Lemmon, E. W., Huber, M. L., and McLinden, M. O., 2007, "Reference Fluid Thermodynamic and Transport Properties," NIST, Gaithersburg, MD, Standard Database 23.

[64] Pope, S. B., 2000, Turbulent Flows, Cambridge University Press, Cambridge, UK.

[65] Komen, E. M. J., Camilo, L. H., Shams, A., Geurts, B. J., and Koren, B., 2017, "A Quantification Method for Numerical Dissipation in Quasi-DNS and UnderResolved DNS, and Effects of Numerical Dissipation in Quasi-DNS and UnderResolved DNS of Turbulent Channel Flows," J. Comput. Phys., 345, pp. 565-595.

[66] Roache, P. J., 1994, "Perspective: A Method for Uniform Reporting of Grid Refinement Studies," ASME J. Fluids Eng., 116(3), pp. 405-413.

[67] Celik, I. B., Ghia, U., Roache, P. J., Freitas, C. J., Coleman, H. W., and Raad, P. E., 2008, "Procedure for Estimation and Reporting of Uncertainty Due to Discretization in CFD Applications," ASME J. Fluids Eng., 130(7), p. 078001.

[68] Mouvanal, S., Burkhardt, A., Chatterjee, D., and Bakshi, S., 2015, "Numerica Prediction of Periodic Cavitation Shedding in Cylindrical Orifice," Proceedings of the International Conference on Liquid Atomization and Spray Systems, Taiwan, China, Aug. 23-27.

[69] Huang, R., Shao, S., Arndt, R. E. A., Luo, X., and Hong, J., 2019 "Numerical Study of the Behaviors of Ventilated Supercavities in a Periodic Gust Flow," ASME J. Fluids Eng., 142(6), p. 061403.

[70] Guo, G., He, Z., Chen, Y., Wang, Q., Leng, X., and Sun, S., 2017, "LES Investigations on Effects of the Residual Bubble on the Single Hole Diesel Injector Jet," Int. J. Heat Mass Transfer, 112, pp. 18-27.

[71] Welch, P. D., 1967, "The Use of Fast Fourier Transform for the Estimation of Power Spectra: A Method Based on Time Averaging Over Short, Modified Periodograms," IEEE T. Audio Electroacoustics, 15(2), pp. 70-73.

[72] Dittakavi, N., Chunekar, A., and Frankel, S., 2010, "Large Eddy Simulation of Turbulent-Cavitation Interactions in a Venturi Nozzle," ASME J. Fluids Eng., 132(12), p. 121301

[73] Wang, C., Wang, G., and Huang, B., 2020, "Characteristics and Dynamics of Compressible Cavitating Flows With Special Emphasis on Compressibility Effects," Int. J. Multiphase Flow, 130, p. 103357. 